UNIVERSIDADE DE SÃO PAULO

FACULDADE DE ODONTOLOGIA DE RIBEIRÃO PRETO

VANESSA LESSA CAVALCANTI DE ARAÚJO

Avaliação volumétrica da obturação dos canais radiculares realizada com diferentes cimentos e técnicas, por meio de microtomografia

Ribeirão Preto 


\title{
Avaliação volumétrica da obturação dos canais radiculares realizada com diferentes cimentos e técnicas, por meio de microtomografia
}

\begin{abstract}
Dissertação de Mestrado apresentada à Faculdade de Odontologia de Ribeirão Preto da Universidade de São Paulo para a obtenção do grau de Mestre em Ciências Programa: Odontologia Restauradora - Área de concentração: Odontologia Restauradora (Opção: Endodontia)
\end{abstract}

Orientador: Prof. Dr. Ricardo Gariba Silva

"Versão corrigida"

\section{Ribeirão Preto}


Autorizo a reprodução e divulgação total ou parcial deste trabalho, por qualquer meio convencional ou eletrônico, para fins de estudo e pesquisa, desde que citada a fonte.

Assinatura do autor:

Data: 12013

FI CHA CATALOGRÁFI CA

Araújo, Vanessa Lessa Cavalcanti de

Avaliação volumétrica da obturação dos canais radiculares realizada com diferentes cimentos e técnicas, por meio de microtomografia. Ribeirão Preto, 2013.

"Versão corrigida da Dissertação. A versão original se encontra disponível na Unidade que se aloja o Programa"

87p. : il. ; $30 \mathrm{~cm}$

Dissertação de Mestrado, apresentada à Faculdade de Odontologia de Ribeirão Preto (FORP/USP). Área de concentração: Odontologia Restauradora - Endodontia.

Orientador: Prof. Dr. Ricardo Gariba Silva.

1. Condensação lateral. 2. Cimentos endodônticos. 3. Microtomografia computadorizada.

"Versão corrigida da Dissertação. A versão original se encontra disnonível na Unidade aue aloia o Proarama." 


\section{FolHa DE APROVAÇÃo}

ARAÚJO, V. L. C. Avaliação volumétrica da obturação dos canais radiculares realizada com diferentes cimentos e técnicas, por meio de microtomografia. 2013. Dissertação (mestrado) - Faculdade de Odontologia de Ribeirão Preto, Universidade de São Paulo, Ribeirão Preto, 2013.

Aprovado em:

\section{Banca Examinadora}

Prof. Dr. Ricardo Gariba Silva (Orientador)

Instituição: Faculdade de Odontologia de Ribeirão Preto/USP

Julgamento:

Assinatura:

Prof (a). Dr (a).

Instituição:

Julgamento:

Assinatura:

Prof (a). Dr (a).

Instituição:

Julgamento:

Assinatura: 

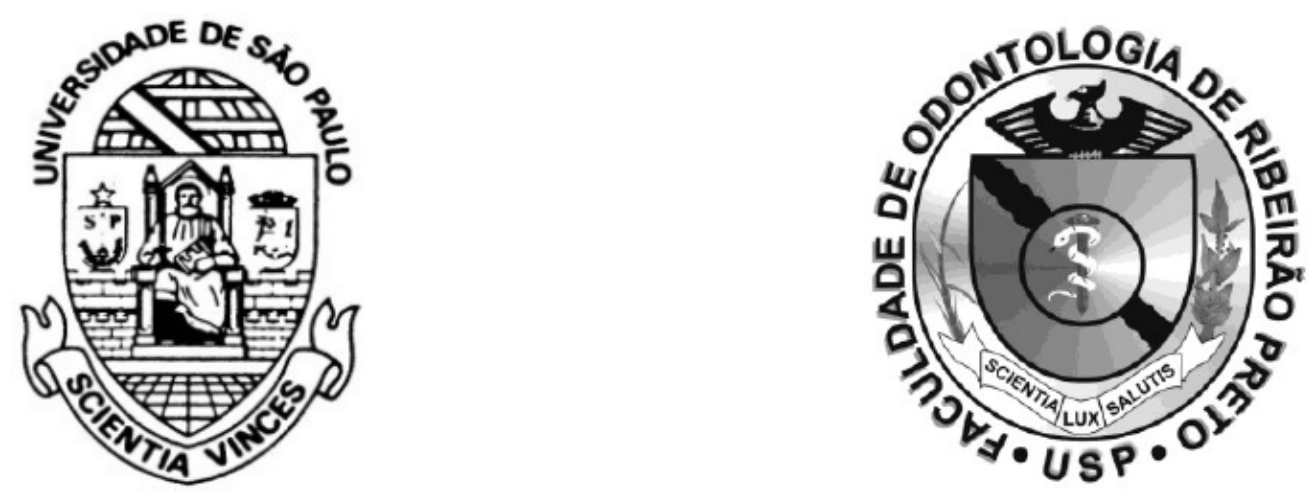

Este trabalho de pesquisa foi realizado no Laboratório de Pesquisa em Endodontia do Departamento de Odontologia Restauradora da Faculdade de Ribeirão Preto da Universidade de São Paulo. 


\section{Dedicatória}


Dedico especialmente este trabalho...

À Deus, por sempre me iluminar e me permitir chegar até aqui;

Aos meus pais, Augusto César Cavalcanti de Araújo e Maria Aparecida Ferreira Lessa, por sempre me apoiarem e me darem força em todos os momentos. Devo a eles todo o meu crescimento, tanto profissional como moral.

Ao meu irmão, amigo, cúmplice e confidente, Vítor Lessa Cavalcanti de Araújo, que sempre está na torcida e confiante do meu futuro. Pessoa maravilhosa e de bom coração, a quem quero todo o bem e sempre por perto de mim.

À minha Tia, Maria Aúrea Cavalcanti de Araújo, que eu tenho como uma segunda mãe e sempre esteve do meu lado, e me incentiva desde o sempre nos meus estudos.

Desculpem-me a minha ausência. A parte mais difícil dessa trajetória foi ficar longe de vocês. Sou muito grata por tê-los em minha vida. Amo todos! 
Agradecimentos 


\section{Agradeço}

Ao meu orientador, Prof. Dr. Ricardo Gariba Silva, por ter me ajudado na construção dessa nova etapa e pelos conhecimentos repassados durante todo o desenvolvimento deste trabalho.

Ao Prof. Dr. Antonio Miranda da Cruz Filho, Prof. Dr. Jesus Djalma Pécora, Prof. Dr. Luiz Pascoal Vansan, Prof. Dr. Manoel Damião de Sousa Neto e ao Prof. Dr. Ricardo Novak Savioli, por acreditarem no meu potencial, me incentivarem e pelos ensinamentos transmitidos com dedicação e profissionalismo.

À Profa. Dra. Aline Evangelista de Souza Gabriel, pela paciência, disposição e colaboração neste trabalho.

Aos Professores do Departamento de Odontologia Restauradora da Faculdade de Odontologia de Ribeirão Preto - Universidade de São Paulo, que por meio das disciplinas ministradas, contribuíram para meu crescimento profissional.

À Profa. Dra. Diana Santana de Albuquerque, responsável pelos meus primeiros passos na arte da Endodontia ainda na graduação. Meus eternos agradecimentos.

Ao funcionário do Departamento da Odontologia Restauradora, Carlos Feitosa dos Santos, um agradecimento em especial por toda ajuda durante essa trajetória, por sua presteza e eficiência.

Aos funcionários, Frederico Augusto B. Farias, Luiza Pitol, Maria I zabel Cezário F. Miguel, Reginaldo Santana, Ronivaldo Zonfrilli e Rosângela Angelini, pelo convívio diário e pelas palavras de incentivo. 
Aos meus amigos da pós-graduação, Amanda Buosi Biagi, Ângelo Rafael Bordin, Diego Augusto Guimarães, Ivan Lobo Gava, Keila de Almeida Franceschini, Emanuele Boschetti, Graziela Bianchi Leoni, Cecília Martins, Jardel Mazzi, Fabiane Lopes, Alessandro Lamira, Rafael Rezende Ribeiro, Rodrigo Dantas, Polliana Vilaça, Luis Eduardo Souza Flamini, Paul Baca Wiesse, Samuel, pelo convívio diário agradável e por todo apoio em todos os momentos.

Às minhas amigas Ana Carla Carvalho, Catarina Borba, Giovanna Rocha de Medeiros e Renata Sampaio que, mesmo distantes, estão sempre presentes na minha vida. Obrigada por poder sempre contar com vocês.

Às minhas amigas Ana Carla Sabini, Lidiane Silva, Gabriela Rezende, Jacqueline Atsuko e Margarete Kochi, pelas palavras de apoio em todos os momentos, pelo companherismo em todas as horas. Vocês tornaram meus dias mais felizes e espero que continuem assim o fazendo.

À toda minha Família, que está sempre torcendo por mim, me dando todo incentivo possível e me fazendo presente em todas às reuniões familiares de todas as maneiras.

À CAPES - Coordenação de Aperfeiçoamento de Pessoal de Nível Superior, pela ajuda financeira.

À Faculdade de Odontologia de Ribeirão Preto, que colaborou com mais um grande passo no meu crescimento profissional.

À todos meus sinceros agradecimentos! 
Sumário 


\section{SUMÁRIO}

\section{Resumo}

Abstract

Introdução

Proposição

Materiais e Método

Resultados $\quad 41$

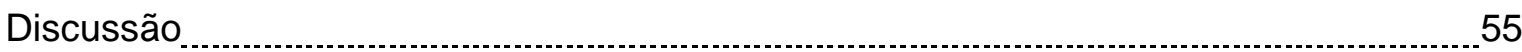

Conclusões 65

Referências Bibliográficas

Apêndices

Anexos 81 


\section{Resumo}


ARAÚJO, V. L. C. Avaliação volumétrica da obturação dos canais radiculares realizada com diferentes cimentos e técnicas, por meio de microtomografia. 2013, 87p. Dissertação (mestrado) - Faculdade de Odontologia de Ribeirão Preto, Universidade de São Paulo, Ribeirão Preto, 2013.

O sucesso do tratamento endodôntico está associado não só com a limpeza e a sanificação do sistema de canais radiculares, mas com a capacidade de selamento do material obturador principalmente do terço apical. O objetivo do presente estudo in vitro foi analisar o volume de guta-percha e de cimento endodôntico no milímetro apical das obturações, utilizando diferentes cimentos e técnicas de condensação. Para tanto, 64 incisivos centrais superiores foram preparados com instrumentos rotatórios de $\mathrm{NiTi}$ até o diâmetro cirúrgico \#60.02, e então distribuídos aleatoriamente em quatro grupos. Para cada um usou-se um cimento diferente, a saber: Endofill, Sealer 26, AH Plus e Sealapex. E para cada cimento utilizado, metade dos dentes foi obturada pela técnica de condensação lateral ativa $(n=8)$, e a outra metade, pela técnica da condensação lateral passiva $(n=8)$. Feitas as obturações, os dentes foram submetidos ao exame tomográfico com o uso do microtomógrafo SkyScan 1174 v2. As imagens foram reconstruídas pelo programa NRecon e em seguida foi avaliado o parâmetro tridimensional do volume de cimento e guta-percha no milímetro apical, por meio do programa CTan. Por meio do teste Tukey, observou-se que o grupo obturado com o Sealer 26 apresentou maior volume de guta-percha no milímetro apical do comprimento de trabalho quando comparado ao Endofill que se apresentou com menor volume $(p>0,05)$. $O$ teste Tukey para 0 fator de variação Cimento endodôntico demonstrou que o grupo obturado com o Sealapex apresentou menor volume de cimento no milímetro estudado quando comparado ao grupo obturado com AH Plus e Sealer 26 ( $p>0,05)$, que evidenciaram maior volume de cimento. Em relação ao fator de variação Técnica obturadora, a condensação lateral ativa apresentou menor volume de cimento comparada técnica passiva $(p>0,05)$. Pode-se concluir que o maior volume de guta-percha foi encontrado nos dentes obturados com o cimento endodôntico Sealer 26, semelhantes aos obturados com Sealapex e AH Plus, independentemente da técnica de condensação. O menor volume de cimento endodôntico foi encontrado no grupo obturado com Sealapex, semelhante ao grupo obturado com o Endofill. Em relação à técnica obturadora, a condensação lateral ativa apresentou menor volume de cimento quando comparada à passiva. 
Abstract 
ARAÚJO, V. L. C. Volumetric evaluation of root canal fillings performed with different sealers and techniques through microtomography. 2013, 87p. Dissertação (mestrado) - Faculdade de Odontologia de Ribeirão Preto, Universidade de São Paulo, Ribeirão Preto, 2013.

The success of endodontic treatment is associated not only with the cleaning and the instrumentation of the root canal system but also with the sealing ability mainly in the apical third of the filling material. The aim of this in vitro study was to analyze the volume of gutta-percha and sealer in the apical millimeter of the fillings, using different obturation technique and sealers. For that purpose, 64 maxillary central incisors were prepared with NiTi rotary instruments until the surgical diameter of \#60.02, and then divided randomly into four groups. For each group, different sealers were used, such as Endofill, Sealer 26, AH Plus and Sealapex. And for each sealer used, half the teeth were obturated using an active lateral condensation technique $(n=8)$, and the other half by passive lateral condensation technique $(n=8)$. After the fillings procedures, samples were examined by SkyScan 1174 v2 micro-CT. Images were reconstructed by NRecon software, and then the dimensional parameter of the volume of sealer and gutta-percha at the apical millimeter was evaluated through the CTan program. The Tukey test showed that the group filled with Sealer 26 had higher volume of gutta-percha at the apical millimeter of working length when compared to that of the Endofill, which presented lower volumes $(p<0.05)$. The Tukey test for the Sealer endodontic variation factor showed that the group filled with Sealapex had the lowest volume of sealer in the studied millimeter when compared to the group filled by $\mathrm{AH}$ Plus and Sealer $26(p<0.05)$, which had the highest volume of sealer. Regarding the filling technique variation factor, the active lateral condensation technique showed lower sealer volume than passive $(p<0.05)$. It can be concluded that the higher volume of gutta-percha was found in teeth filled with sealer Sealer 26 , similar to Sealapex and AH Plus, regardless of the technique of condensation. The lowest volume of sealer was found in the group filled with Sealapex, similar to the group filled with Endofill. Regarding the obturation technique, the active lateral condensation technique showed lowest volume of sealer than the passive. 


\section{Introdução}



A complexidade da anatomia do sistema de canais radiculares (SCR) gera desafios e dificuldades clínicas que podem prejudicar o objetivo principal da terapia endodôntica. A porção correspondente aos milímetros finais do canal, que abriga além do canal radicular principal, inúmeras ramificações, como deltas ou foraminas apicais, canais acessórios e secundários, evidencia a necessidade de se obter um selamento satisfatório. Deste modo, a partir de um eficiente selamento apical, impedir-se-á a entrada, no interior do sistema de canais, de fluidos teciduais oriundos do periápice, assim como a saída de microrganismos residuais que sobreviveram ao preparo químico-mecânico e seus produtos para os tecidos perirradiculares (LUCCY; WELLER; KULILD, 1990; PABLO et al., 2010).

Assim, uma obturação, para ser considerada satisfatória, deve propiciar o preenchimento de todo o espaço preparado, modelado e limpo do canal radicular, de forma tridimensional, tanto do canal principal quanto dos acessórios, de forma a facilitar o reparo biológico do periápice (SCHILDER, 1967). A obturação tridimensional dos canais radiculares, bem compactada, previne a percolação e a microinfiltração de exsudatos periapicais para o interior do espaço dos canais, a reinfecção e cria ambiente biológico favorável para a cura (WU; DUMMER; WESSELINK, 2006; MINER; BERZINS; BABCALL, 2006; ARI; BELLI; GUNES, 2010).

Os materiais obturadores dos canais devem ser de fácil introdução no canal radicular, devem obliterar o canal, tanto lateral como apicalmente, não devem apresentar contração após serem inseridos, devem ser impermeáveis à umidade, bacteriostáticos ou pelo menos impróprios ao crescimento microbiano, radiopacos, não devem manchar a estrutura dentinária, estéreis ou passíveis de serem esterilizados de modo fácil e rápido, não devem irritar o tecido periapical, além de 
serem de fácil remoção do canal radicular quando isto se fizer necessário (ØRSTAVIK, 2005; JAMES et al., 2007).

A eficiência de um material para vedar adequadamente o espaço do canal radicular é estabelecida por suas propriedades físicas e características de manipulação. Nenhum material foi tão bem sucedido e amplamente aceito como a guta-percha como material de preenchimento, pois possuem muitas propriedades favoráveis, que incluem a sua biocompatibilidade, plasticidade, compatibilidade, radiopacidade e sua fácil introdução e remoção quando necessário (DEITCH et al., 2002; LEA et al., 2005; MINER; BERZINS; BABCALL, 2006; GULSAHI et al., 2007a; JAMES et al., 2007). Porém, a guta-percha não tem capacidade de adesão às paredes dentinárias, resultando assim na formação de lacunas entre os cones e as paredes do canal. Portanto o uso de guta-percha associado ao cimento endodôntico deve ser utilizado na obturação do SCR para todas as técnicas, e tem permanecido o padrão de atendimento na endodontia (CHANDRASEKBAR et al., 2011; CHENG et. al., 2012).

A qualidade de preenchimento tridimensional do cimento é um pré-requisito para a vedação do SCR. O cimento tem como função essencial impermeabilizar o sistema de canais radiculares, agrupar a massa obturadora facilitando a sua adaptação à superfície dentinária, como também função lubrificante, que facilita o movimento do cone de guta-percha e preenche as irregularidades dos canais, onde a guta-percha não consegue alcançar (GROSSMAN, 1958; SILVA et al., 2013).

É essencial utilizar um cimento que forme uma película de espessura mínima, afim de que fique adjacente às paredes dos canais. Além disso, com essa camada fina, o cimento também pode penetrar mais profundamente nas irregularidades do canal (MARCIANO et al., 2011). O resultado ideal na obturação é ter um grande 
volume de guta-percha e um volume mínimo de cimento no interior do canal radicular principal, tendo penetração maior sobre as suas irregularidades e túbulos dentinários (SOUZA et al., 2009). A penetração dos cimentos nos túbulos dentinários pode ser biologicamente benéfica, porque os estudos de laboratório demonstraram que os cimentos podem exercer efeitos antibacterianos nos túbulos dentinários infectados, principalmente na ausência de smear-layer (ORDINOLAZAPATA et al., 2009).

No intuito de se conquistar as melhores características do material obturador, diferentes cimentos endodônticos foram propostos, destacando-se os materiais à base de Óxido de Zinco e Eugenol (Endofill, FillCanal, N-Rickert, Grossman), de ionômero de Vidro (Ketac Endo, Active GP), que contêm hidróxido ou óxido de cálcio (Sealapex, Apexit), silicone (Guttaflow, RockoSeal) e os cimentos resinosos (AH 26, Sealer 26, AH Plus, Epihany), que se tornaram mais popular devido às suas propriedades adesivas (ØRSTAVIK, 2005; GARRIDO et al., 2010; CHANDRASEKBAR et al., 2011; FLORES et al., 2011; CECCHIN et al., 2012).

Os cimentos à base de óxido de zinco e eugenol ainda são amplamente utilizados. São eles, o cimento de Rickert, na forma comercial como Kerr Pulp Canal Sealer, e cimento de Grossman, que tem várias formas comerciais variantes, entre eles o cimento Endofill, Roth e ProcoSol. Rickert adicionou pó de prata para o melhor contraste, enquanto Grossman utilizou sais de bário e bismuto. Esses cimentos têm atividade antibacteriana própria, mas também exibem alguma toxicidade quando colocados diretamente em tecidos vitais (ØRSTAVIK, 2005).

Os cimentos à base de ionômero de vidro foram considerados biocompatíveis e também mostraram adesão à dentina, porém achados laboratoriais identificaram 
efeitos desagradáveis, como a sua degradação, levando à infiltração (SCHÄFER; ZANDBIGLARI, 2003).

Sealapex e Apexit são marcas conhecidas de cimentos que contêm hidróxido de cálcio. Sealapex contém óxido de cálcio, salicilato, fosfato tricálcico, sílica e trióxido de bismuto, na sua composição. A razão para a adição de hidróxido de cálcio nos materiais obturadores emana a partir de observações de forros e bases com esse material nas suas composições, o seu efeito antibacteriano e suas habilidades de reparo tecidual (ØRSTAVIK, 2005), além de colagenização e mineralização (GARRIDO et al., 2010). Quando indicado como um material obturador, os íons de cálcio que são liberados favorecem a ocorrência de pH mais alcalino do ambiente, culminando com a aceleração do processo de reparação (BORGES et al., 2012). Essas características também são apresentadas com Sealer 26 que contém hidróxido de cálcio, trióxido de bismuto, hexametileno tetramina e dióxido de titânio, porém é um cimento à base de resina epóxica (GARRIDO et al., 2010).

As resinas sintéticas vêm sendo usadas como cimentos ao longo do tempo. Os cimentos mais bem sucedidos são os da série AH. AH Plus (Dentsply De Trey Gmbh, Konstanz, Alemanha), uma mistura de epóxi-aminas, é frequentemente usado como material controle nas pesquisas (ØRSTAVIK, 2005; RESENDE et al., 2009), devido às suas propriedades, que incluem longa estabilidade dimensional, solubilidade reduzida, bom selamento apical, microretenção com a dentina e baixa toxicidade. Contém óxido de zirconio, óxido de ferro e tungstato de cálcio (VERSIANI et al., 2006, GARRIDO et al., 2010). 
Embora vários tipos de cimentos endodônticos tenham sido propostos como materiais obturadores inovadores, o cimento ideal ainda tem de ser encontrado (VERSIANI et al., 2006; RESENDE et al., 2009, FLORES et al., 2011).

Existe uma variedade de técnicas usadas na obturação do SCR, entre elas, a condensação lateral a frio, que oferece a vantagem da colocação controlada de guta-percha no conduto radicular (DEITCH et al., 2002; LEA et al., 2005). Em geral, a técnica da condensação lateral é previsível e relativamente simples de executar regularmente em canais cônicos (DE-DEUS et al., 2008). Foi concebida por CALLAHAN (1914), e tem sido o método de obturação do sistema de canais radiculares mais utilizado nos últimos anos. É também utilizada como técnica padrão, para comparação com outras técnicas de obturação de canais radiculares (PETERS; SONNTAG; PETERS, 2010).

SOUZA et al. (2009) citaram uma preocupação relacionada com a técnica de condensação lateral passiva quanto a possibilidade de obturação coronal prematura, considerando que os cones acessórios apresentam maior diâmetro na porção coronal, proporcionando o preenchimento prematuro desse terço e inviabilizando uma melhor vedação apical. Portanto essa técnica seria melhor empregada em canais suficientemente cônicos, porém clinicamente é impossível avaliar o formato do canal radicular. Já com a técnica de condensação lateral ativa, emprega-se o uso dos espaçadores digitais, oferecendo mais espaços entre o cone principal e as paredes do canal radicular, permitindo realizar a obturação com maior número de cones acessórios, sendo melhores adaptados dentro do canal e condensados mais apicalmente e lateralmente. Quando o espaçador não consegue mais penetrar indica que a porção apical está bem obturada e que não existe mais espaço para compactação da guta-percha. O espaçador digital é ajustado para que seja inserido 
um a dois milímetros aquém do comprimento de trabalho, sendo o processo repetido até que ele não ultrapassse mais o terço cervical (GORDON; LOVE; CHANDLER, 2005). Estudos mostram que o melhor selamento apical usando a técnica de condensação lateral ativa, é obtido quanto mais próximo do comprimento de trabalho o espaçador conseguir alcançar (NIELSEN; BAUMGARTNER, 2006; SAATCHI; ETESAMI, 2006).

As variações de anatomia do SCR e as diversas técnicas de obturação influenciam significantemente a porcentagem de guta-percha nos canais obturados (GORDON; LOVE; CHANDLER, 2005; SOUZA et al., 2009). WU et al. (2000) em seu estudo, já havia concluído que a discrepância do formato dos canais radiculares entre os mais arredondados ou mais ovalados e estreitos pode dificultar a limpeza e modelagem do SCR, como também influencia no momento da obturação.

A condensação lateral ao frio pode produzir melhores obturações em canais redondos do que em canais ovais, pois com ela é mais difícil preencher as áreas mais achatadas dos canais ovais. Porém, mesmo os canais mais ovalados tendem para uma secção transversal arredondada nos milímetros mais apicais, o que explica o porquê do seu uso em alguns estudos assim como o emprego da técnica aquecida, sendo que ambos os procedimentos mostraram resultados do selamento apical bem semelhantes (WU et al., 2000; WU; KAŠT'ÁKOVÁ; WESSELINK, 2001). Já nos terços coronal e cervical, as obturações com a técnica da condensação lateral aquecida apresentaram qualidades de preenchimento significantemente melhores do que a condensação lateral ao frio (COLLINS et al., 2006).

Existem alguns métodos que permitem a avaliação da obturação do SCR, como as imagens radiográficas, penetração de corantes, filtração de fluidos, diafanização e até mesmo o corte seriado da raiz (DOWKER; DAVIS; ELLIOTT, 
1997). Porém todos esses métodos possuem limitações. A radiografia apesar de ser um método não destrutivo, só projeta a imagem em duas dimensões. A penetração de corantes avalia apenas o terço apical do dente. A filtração de fluidos requer grande tempo de observação. A diafanização é um processo irreversível de desmineralização, desidratação e clarificação, modificando assim a estrutura do dente e o corte histológico é um método destrutivo (NIELSEN et al., 1995; JARRET et al., 2004; NASERI et al., 2013).

A microtomografia computadorizada de alta resolução ( $\mu \mathrm{CT}$ ) é uma técnica reprodutível não invasiva, não destrutiva e que não exige a preparação dos dentes submetidos à análise. Os dados podem ser representados em 2D ou 3D, e seus cortes recriados em qualquer plano. As imagens do SCR podem ser analisadas qualitativamente e quantitativamente (RHODES et al., 1999; YIN et al., 2010; VIERPELISSER et al., 2010; SOMMA et al., 2011; VERSIANI; PÉCORA; SOUSA-NETO, 2011a; VERSIANI; SOUSA-NETO; PÉCORA, 2011), permitindo avaliar formas tridimensionais, volumes dos canais radiculares na Endodontia experimental (IKRAM et al., 2009; MOORE; FITZ-WALTER; PARASHOS, 2009; VIER-PELISSER et al., 2010), além de ser uma ferramenta muito útil para o estudo da anatomia interna e externa dos dentes, demonstrada simultaneamente ou separadamente (PLOTINO et al., 2006).

A $\mu$ CT permite a obtenção de imagens com boa resolução geométrica, em tempos relativamente curtos de aquisição, mediante procedimentos operacionais simples, protocolos de varredura rápidos, com baixos custos de aquisição e manutenção do aparelho (SCHAMBACH et al., 2010), com possibilidade de observar ex vivo fraturas dentais, lesões cariosas, secções do esmalte e da dentina (NAGASAWA et al., 2010), detectar a presença de espaços vazios e defeitos 
internos (GANDOLFI et al., 2013), estudar as técnicas de preparo do canal radicular (PETERS; BOESSLER; PAQUÉ, 2010), porém com a limitação de amostras experimentais reduzidas (PETERS; PAQUÉ, 2011). Com a nova geração de aparelhos de $\mu \mathrm{CT}$ conectados a computadores de alta performance (PLOTINO et al., 2006), é possível avaliar de forma precisa e não-invasiva a anatomia, o preparo e a obturação do SCR, utilizando programas específicos (JUNG; LOMMEL; KLIMEK, 2005).

Diante do entendimento de que o prognóstico do tratamento endodôntico está vinculado ao preparo e obturação do SCR (VERTUCCI, 2005; GILLEN et al., 2011), é relevante a avaliação de todas estas etapas sequencialmente, utilizando metodologias não destrutivas, como a microtomografia computadorizada, que permitam maior precisão dos resultados, a fim de demonstrar a eficiência dos materiais obturadores e das técnicas de obturação dentro do arsenal disponível, visando o selamento hermético do SCR, com materiais que permitam atingir o sucesso da terapêutica endodôntica, expresso por meio da reparação biológica dos tecidos apicais e periapicais, e, se possível, sem a presença de microorganismos. 


\section{Proposição}



O objetivo deste estudo in vitro foi analisar, por meio de microtomografia computadorizada, os volumes de guta-percha e de cimento endodôntico, presentes no milímetro apical das obturações dos canais radiculares realizadas com a técnica de condensação lateral ativa e de passiva, utilizando-se quatro cimentos diferentes, sendo eles: Endofill, Sealapex, AH Plus e o Sealer 26. 

Materiais e Método 



\section{Seleção da amostra}

Após a aprovação do presente estudo pelo Comitê de Ética em pesquisa pela Faculdade de Odontologia de Ribeirão Preto, Universidade de São Paulo (Anexo 1), foram obtidos, do banco de dentes da FORP-USP, 64 incisivos centrais superiores humanos, com rizogênese completa e estrutura radicular hígida, mantidos em solução de timol a $0,1 \%$ até o momento do uso. Após serem lavados em água corrente por 24 horas, tiveram suas superfícies radiculares externas limpas com o auxílio do ultrassom (Profi II Ceramic, Dabi Atlante Ltda, Ribeirão Preto, SP, Brasil). Cada espécime foi colocado em tubos de ensaio contendo soro fisiológico e armazenado em estufa $\left(37^{\circ} \mathrm{C}, 100 \%\right.$ de umidade relativa, por 72 horas), visando à sua reidratação.

\section{Preparo dos corpos de prova}

Inicialmente foi realizada a cirurgia de acesso, com ponta esférica diamantada (Microdont LTDA, Socorro, SP, Brasil) variando sua numeração com o tamanho da coroa dental, acionada em alta rotação (Dabi Atlante, Ribeirão Preto, SP, Brasil), sob refrigeração, tomando-se o cuidado de remover completamente o teto da câmara pulpar e de deixar as paredes da cavidade de acesso divergentes e sem retenções, seguida da irrigação com hipoclorito de sódio a $1 \%$ nos canais radiculares, com o uso de seringa plástica descartável (Ultradent Products Ins., South Jordan, UT, EUA) e agulha NaviTip (Ultradent Products Ins., South Jordan, UT, EUA). Com o canal inundado, foi realizada a exploração do canal foi realizada com lima manual tipo K \#10 (Dentsply, Maillefer, Baillagues, Suiça), seguida do preparo cervical com as brocas LAAXXES 20.06, 35.06, 45.06 (SybronEndo, Orange, CA, EUA) respectivamente, montadas em micromotor, em baixa rotação e sem irrigação, que 
foram introduzidas no canal com movimento de penetração e saída com leve pressão, até que houvesse resistência à penetração, observado o máximo correspondente a um terço do comprimento do dente, em direção à região de ombro palatino, para a sua remoção de modo a permitir o acesso dos instrumentos ao canal radicular, sem interferências. Concluído o preparo cervical, foi realizada a toalete da cavidade por meio de irrigação abundante com solução de hipoclorito de sódio a 1\%. Com o canal inundado pela solução irrigadora, introduziu-se uma lima manual tipo K \#10 (Dentsply, Maillefer, Baillagues, Suiça), até que sua ponta coincidisse com o forame apical. Então foi medido o comprimento do canal e subtraído $1 \mathrm{~mm}$ para o estabelecimento do comprimento de trabalho (CT).

Todos os espécimes foram instrumentados até 0 diâmetro final correspondente ao do instrumento 60 na extremidade apical do CT, com limas rotatórias K3 Endo (SybronEndo, Glendora, CA, EUA), de acordo com a técnica Free Tip Preparation, que preconiza movimentos de bicadas, tendo seus canais irrigados com $2 \mathrm{~mL}$ hipoclorito de sódio a $1 \%$ a cada troca do instrumento, seguindo a seguinte sequência: 20.02, 20.04, 25.06, 25/.02, 25/.04, 25/.06, 30/.02, 30/.04, 25/.06, 35/.02, 25/.06, 40/.02, 25/.06, 45/.02, 25/.06, 50/.02, 25/.06, 55/.02, 25/.06, e por fim foi realizado o batente apical com o instrumento 60/.02 do sistema K3 Endo, a partir do seu diâmetro inicial pré-estabelecido. Os instrumentos com taper .02 e .04 foram introduzidos até o CT, e a lima 25.06 apenas no terço médio/cervical do canal.

Após o preparo do canal, foi feita a irrigação final com a solução de ácido etilenodiaminotetracético (EDTA) a 17\%, por 5 minutos e, em seguida, novamente com hipoclorito de sódio a $1 \%$. Foi realizada então a secagem dos canais com pontas de papel absorventes \#60.02 (Dentsply Maillefer, Petrópolis, Brasil). 
Para a fase de obturação, os 64 dentes foram separados aleatoriamente em quatro grupos, e para cada um usou-se um cimento diferente, a saber: Endofill, Sealer 26, AH Plus e Sealapex. Para cada cimento utilizado, metade dos dentes foi obturada pela técnica de condensação lateral ativa $(n=8)$, e a outra metade, pela técnica da condensação lateral passiva $(n=8)$, conforme exposto na Figura 1. Para a obturação, os cimentos foram manipulados de acordo com as orientações do fabricante.

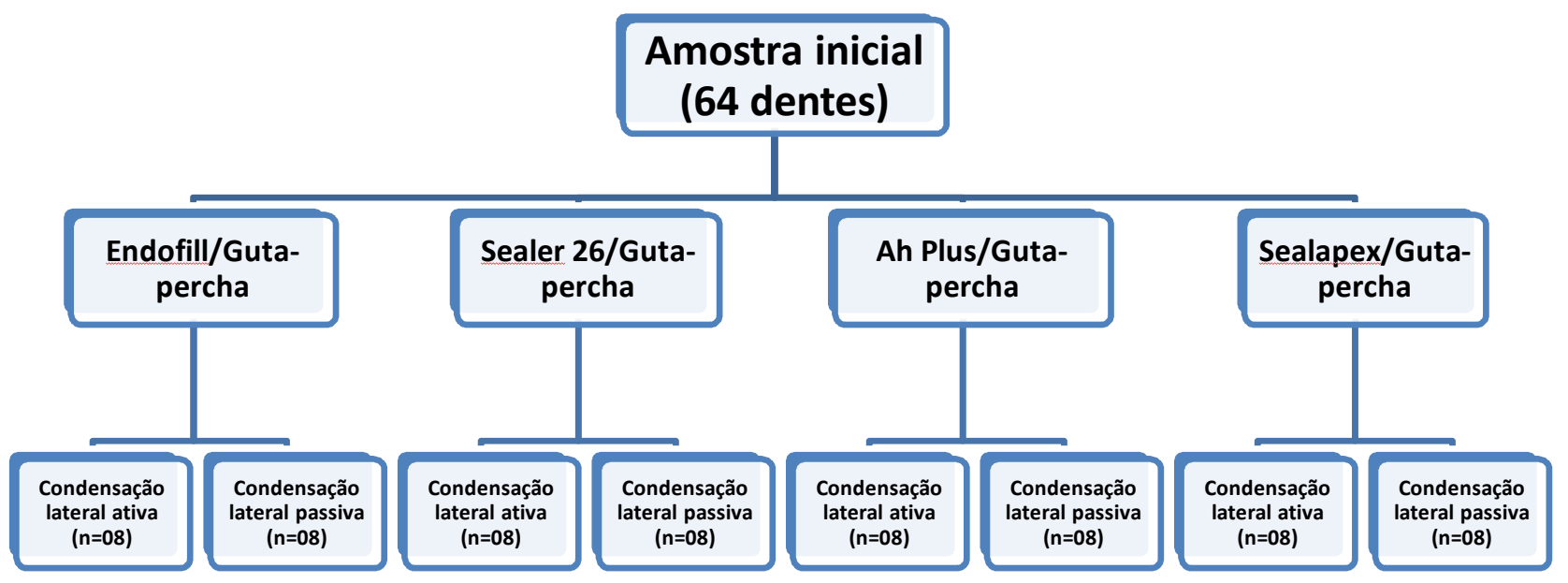

Figura 1. Esquema de divisão dos grupos estudados, divididos de acordo com o cimento obturador e a técnica de obturação utilizada.

Os cones principais de guta-percha de diâmetro 60/.02 foram selecionados por meio dos testes visual - percorreu todo o comprimento de trabalho, tátil - travou no comprimento de trabalho, e radiográfico - estava no comprimento de trabalho radiográfico. Nos espécimes que foram obturados pela técnica da condensação lateral passiva, o cone principal envolto pelo cimento obturador foi assentado no interior do canal radicular, seguido da colocação passiva de cones acessórios R7 (Dentsply, Maillefer, Petrópolis, Brasil) envoltos com cimento, até que não foi mais possível inseri-los. Após confirmação da obturação por meio de radiografia, os cones de guta-percha foram cortados com calcador tipo Paiva aquecido, e foi realizada a 
condensação vertical da obturação com outro calcador tipo Paiva, frio, com diâmetro menor que o diâmetro da entrada do canal. Nos dentes obturados pela técnica da condensação lateral ativa, o cone principal envolto pelo cimento obturador foi assentado no interior do canal radicular e, com o auxílio do espaçador digital, que foi inserido até que não mais penetrasse no canal, observado o máximo de $1 \mathrm{~mm}$ aquém do comprimento de trabalho, foi criado espaço para a introdução de cones acessórios. Os cones foram adicionados, até que o espaçador não penetrasse no canal. Em seguida foi realizado o corte e a condensação vertical da obturação como já descrito anteriormente.

Após serem obturados, foi procedida a toalete da câmara pulpar com algodão e álcool e todos os espécimes foram vedados com cimento de óxido de zinco e eugenol, e inseridos em tubos de ensaio vazios, devidamente separados e identificados de acordo com o tipo de cimento e a técnica de obturação utilizada, e novamente armazenados na estufa (a $37^{\circ} \mathrm{C}$ E $100 \%$ de umidade relativa) por um tempo equivalente a $3 x$ o tempo de endurecimento do cimento utilizado, aguardando a segunda parte do estudo.

\section{Exame Tomográfico}

Feitas as obturações, os dentes foram submetidos ao exame tomográfico com o uso de microtomógrafo compacto SkyScan 1174 v2 (Bruker-microCT, Kontich, Bélgica) (Figura 2A), do Departamento de Odontologia Restauradora da FORP-USP, cujos parâmetros de exposição foram estabelecidos em 50 kV, 800 mA, 40 W de potência máxima, resolução espacial estabelecida em 16,7 $\mu \mathrm{m}$ de tamanho do pixel, para o ciclo de evolução da tomada tomográfica estabelecido em $360^{\circ}$ (Anexo 2). Para isso, cada espécime foi colocado na câmara de exposição do aparelho, ali permanecendo durante todo o ciclo. Foi ainda utilizado filtro de $0,5 \mathrm{~mm}$ de alumínio 
posicionado em frente à fonte de raios- $X$, que permitiu alterar a sensibilidade à radiação policromática. Em seguida, procedeu-se à correção do campo de aquisição por meio da ferramenta flat-field correction usando o programa de controle SkyScan 1174 v2.
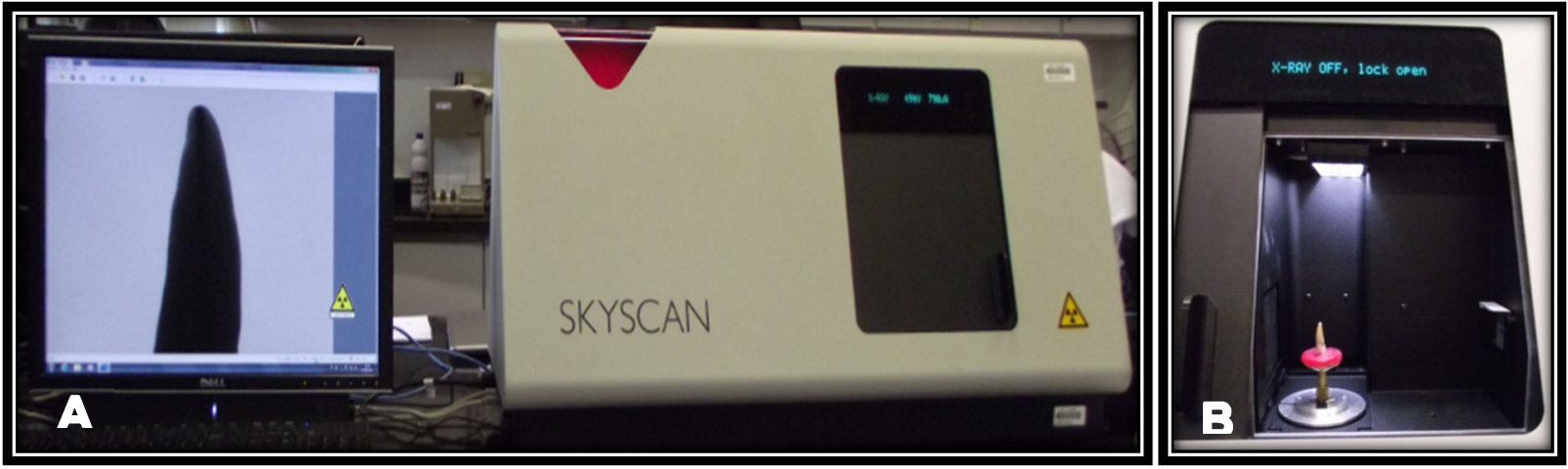

Figura 2. (A) Microtomógrafo compacto SkyScan 1174 v2 (Bruker-microCT, Kontich, Bélgica), conectado ao computador Dell Precision T5500 WorkStation. (B) Posicionamento do espécime no interior da câmara do micotomógrafo.

Cada espécime foi acoplado individualmente a um posicionador metálico com cera utilidade, que possibilitou o seu posicionamento de forma perpendicular em relação à fonte de radiação durante o escaneamento, reduzindo-se assim a possibilidade de distorção da imagem. O posicionador era firmemente fixado a uma mesa giratória, por meio de um parafuso de controle manual (Figura 2B).

Após o posicionamento do dente e fechamento do compartimento da câmara do microtomógrafo, a fonte de raios-X era acionada por meio do botão de energia na barra de ferramentas do Programa de Controle SkyScan 1174 v2. Depois do processo de aging, correspondente ao pré-aquecimento do tubo de raios- $\mathrm{X}$, no qual a tensão e a corrente sobem suavemente, verificou-se a correta posição do espécime com auxílio da ferramenta Video Image.

Uma vez confirmado o posicionamento, definiu-se uma quantidade total de 2 quadros (frames) tomados em cada projeção angular com tamanho de voxel 
isotrópico de 16,7 $\mu \mathrm{m}$. Essa manobra permitiu calcular a média dos sinais e assim a definição final de cada imagem, estabelecendo um tempo de escaneamento de aproximadamente 45 minutos por espécime.

A etapa seguinte na reconstrução das secções transversais a partir das imagens das projeções angulares por meio do algoritmo de reconstrução de feixe cônico de Feldkamp modificado, usando o programa NRecon v.1.6.6.0 (BrukermicroCT, Kontich, Bélgica), resultando na completa representação da microestrutura interna de cada dente. Neste sentido, foi aplicada redução de artefatos em forma de anel (ring artifact) no valor de 5 (escala de 0-20), de endurecimento de feixe (beam hardening) no percentual de $15 \%$ (escala de o a 100\%), de suavização (smoothing) no valor de 3 (escala de 0 a 10) e com o histograma de contraste no modo logarítimo variando de 0,012 (valor mínimo) a 0,50 (valor máximo) (Anexo 3).

Após a reconstrução, realizou-se o processamento e análise das imagens com auxílio do programa CTan v.1.13.5.1+ (Bruker-microCT, Kontich, Bélgica) que consistiu, inicialmente, na utilização de operações matemáticas para alterar valores dos pixels do canal radicular, em um processo denominado de binarização ou segmentação. Estas operações matemáticas consistiram na elaboração e execução de uma rotina computacional por meio da ferramenta Custom Processing, utilizando uma sequência de plug-ins, visando a padronização e automatização do processo de obtenção de dados.

O primeiro passo consistiu na segmentação da imagem por meio da técnica de limiarização ou threshold interativo no qual a segmentação dos valores de cinza foi obtida de forma interativa, separando-se os segmentos que corresponderiam à dentina e ao canal radicular. 
Obtidas as imagens utilizando-se o software NRecon, que acompanha e gerencia todo o funcionamento do microtomógrafo, foi determinado o volume da guta-percha e de cimento na massa obturadora, valendo-se apenas dos 60 primeiros cortes obtidos a partir do início da evidenciação do cone principal de guta percha, que foram assinaladas como sendo a região de interesse (ROI) para o estudo, e que equivale a aproximadamente $1 \mathrm{~mm}(60$ cortes $X 16,7 \mu \mathrm{m}=1002 \mu \mathrm{m})$, referente ao $\mathrm{mm}$ apical do CT.

\section{Análise Estatística}

Uma vez que os dados de volume de guta-percha e de cimento endodôntico apresentaram distribuição normal (Shapiro-Wilk, p>0,05) e homogeneidade de variância (teste de Levene, $p>0,05$ ), foram utilizados testes paramétricos para análise estatística dos dados. Análise de variância a dois critérios foi usada para avaliar a influência do cimento endodôntico (AH Plus, Endofill, Sealer 26 e Sealapex), da técnica obturadora (Condensação lateral ativa e passiva) e da interação dos fatores (Cimento x Técnica) em relação ao volume de guta-percha e de cimento endodôntico no milímetro apical do comprimento de trabalho. O teste de Tukey foi usado para comparações múltiplas entre os grupos. Os testes estatísticos foram realizados usando programa SPSS versão 17 (LEAD Technologies, Inc., Chicago, IL, EUA). 

Resultados 

Os dados apresentados neste estudo correspondem aos volumes de gutapercha e de cimento endodôntico presentes na massa obturadora localizada no milímetro apical do comprimento de trabalho de obturações dos canais radiculares realizadas com o procedimento de condensação lateral ativa e passiva, utilizando quatro diferentes cimentos, sendo eles: Endofill, Sealapex, AH Plus e Sealer 26. Os valores das médias e desvios-padrão obtidos a partir dos dados originais, que constam na tabela contida no Apêndice, estão demonstrados na Tabela 1.

Tabela 1. Médias \pm desvios-padrão dos volumes $\left(\mathrm{mm}^{3}\right)$ de cimento e guta-percha presentes no milímetro apical do comprimento de trabalho de obturação dos quatros diferentes cimentos endodônticos, feitos com a técnica de condensação lateral ativa e passiva, obturados obtidas a partir dos dados originais.

\begin{tabular}{|c|c|c|c|c|c|c|}
\hline \multirow{2}{*}{\multicolumn{3}{|c|}{$\begin{array}{c}\text { Material } \\
\text { Técnica }\end{array}$}} & \multicolumn{2}{|c|}{ Cimento } & \multicolumn{2}{|c|}{ Guta-percha } \\
\hline & & & Passiva & Ativa & Passiva & Ativa \\
\hline \multirow{4}{*}{ 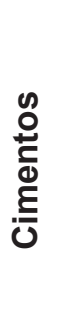 } & \multirow{4}{*}{ 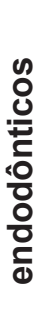 } & AH Plus & $0,115 \pm 0,009$ & $0,108 \pm 0,005$ & $0,309 \pm 0,055$ & $0,319 \pm 0,073$ \\
\hline & & Endofill & $0,108 \pm 0,008$ & $0,099 \pm 0,011$ & $0,266 \pm 0,038$ & $0,271 \pm 0,032$ \\
\hline & & Sealapex & $0,101 \pm 0,005$ & $0,098 \pm 0,012$ & $0,285 \pm 0,023$ & $0,317 \pm 0,051$ \\
\hline & & Sealer 26 & $0,122 \pm 0,016$ & $0,096 \pm 0,010$ & $0,313 \pm 0,072$ & $0,328 \pm 0,02$ \\
\hline
\end{tabular}

\section{Volume de guta-percha em relação à massa obturadora total}

A análise de variância para o volume de guta-percha demonstrou haver diferença estatisticamente significante para o fator cimento endodôntico $(p=0,023)$. Não houve diferença estatisticamente significante para a técnica obturadora ( $p=0,222)$ e para a interação dos fatores (cimento endodôntico x técnica obturadora) $(p=0,896)($ Tabela 2$)$. 
Tabela 2. Análise de Variância a dois critérios para valores de volume de guta-percha no milímetro apical de obturação em relação aos cimentos obturadores e as técnicas de obturação e suas interações.

\begin{tabular}{|c|c|c|c|c|c|}
\hline Fator & GL & $\begin{array}{l}\text { Soma dos } \\
\text { quadrados }\end{array}$ & $\begin{array}{l}\text { Média dos } \\
\text { quadrados }\end{array}$ & $\begin{array}{c}\text { Valor de } \\
\text { F }\end{array}$ & $\begin{array}{c}\text { Valor de } \\
\text { P }\end{array}$ \\
\hline Cimento endodôntico & 3 & 0,0258 & 0,00862 & 3,445 & $0,023^{*}$ \\
\hline Técnica obturadora & 1 & 0,00381 & 0,00381 & 1,524 & 0,222 \\
\hline $\begin{array}{l}\text { Cimento endodôntico } \\
\text { x Técnica obturadora }\end{array}$ & 3 & 0,0015 & 0,000500 & 0,200 & 0,896 \\
\hline Residual & 56 & 0,140 & 0,00250 & & \\
\hline Total & 63 & 0,171 & 0,00272 & & \\
\hline
\end{tabular}

${ }^{*}$ Diferença estatisticamente significante entre os grupos $(p<0,05)$.

O teste de Tukey demonstrou que, independente da técnica, o grupo de dentes obturado com o Sealer 26 apresentou maior volume de guta-percha no milímetro apical do comprimento de trabalho diferindo estatisticamente apenas do grupo de dentes obturado com Endofill, que por sua vez apresentou menor volume de guta-percha $(p>0,05)$. E resultados intermediários foram obtidos pelos grupos dos dentes obturados pelo AH Plus e o Sealapex (Tabela 3).

Tabela 3. Médias \pm desvios-padrão do volume de guta-percha nos diferentes grupos.

\begin{tabular}{cc}
\hline Grupos experimentais & Média Geral \\
\hline Dentes obturados com AH Plus & $0,314 \pm 0,625 \mathrm{AB}$ \\
Dentes obturados com Endofill & $0,268 \pm 0,034 \mathrm{~B}$ \\
Dentes obturados com Sealapex & $0,301 \pm 0,042 \mathrm{AB}$ \\
Dentes obturados com Sealer 26 & $0,320 \pm 0,053 \mathrm{~A}$
\end{tabular}

* Letras diferentes indicam diferença estatística entre os grupos experimentais ao teste de Tukey $(p<0,05)$

A Figura 4 ilustra o gráfico das médias comparando o volume de guta-percha presente no milímetro apical do comprimento de trabalho entre os cimentos endodônticos. 


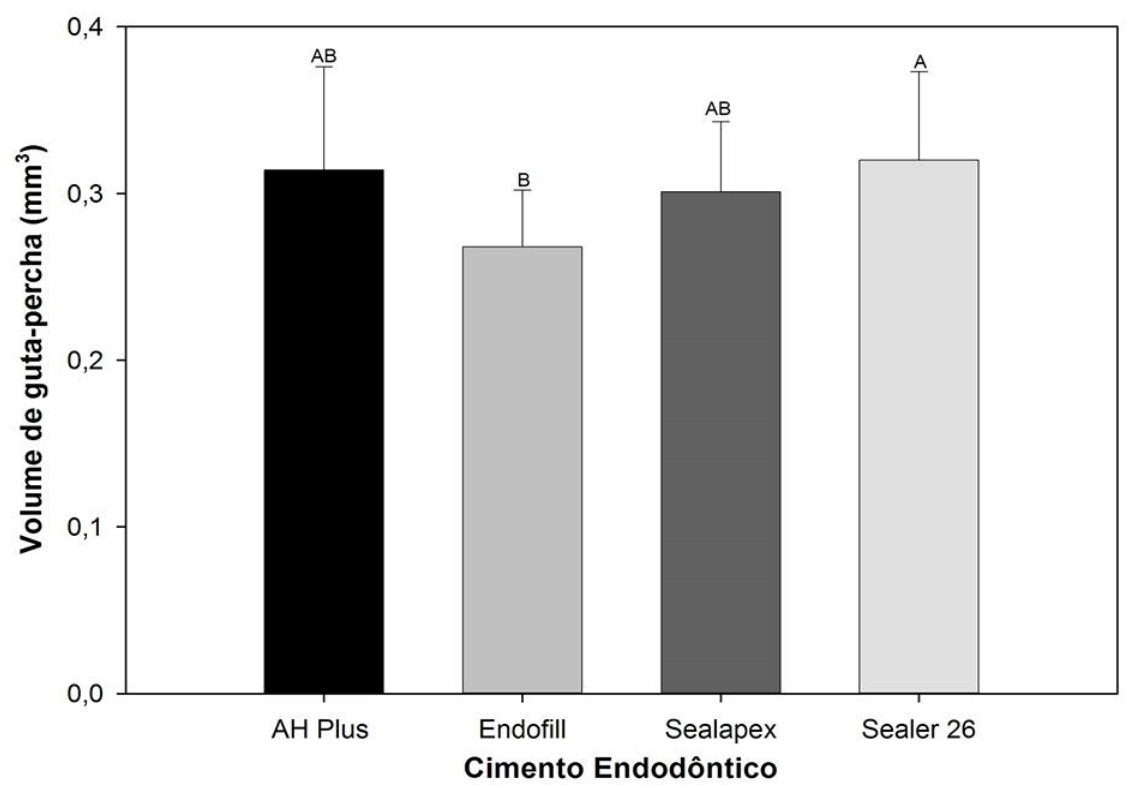

Figura 4. Gráfico esquemático comparando o volume em $\mathrm{mm}^{3}$ de guta-percha no milímetro apical do comprimento de trabalho entre os grupos de cimento endodôntico.

A Figura 5 ilustra o gráfico da diferença das médias dos valores de volume de guta-percha no milímetro apical do comprimento de trabalho comparando a técnica de condensação lateral ativa $(0,309 \pm 0,052 \mathrm{~A})$ e passiva $(0,293 \pm 0,052 \mathrm{~A})$, que não diferiram estatisticamente entre si $(p>0,05)$.

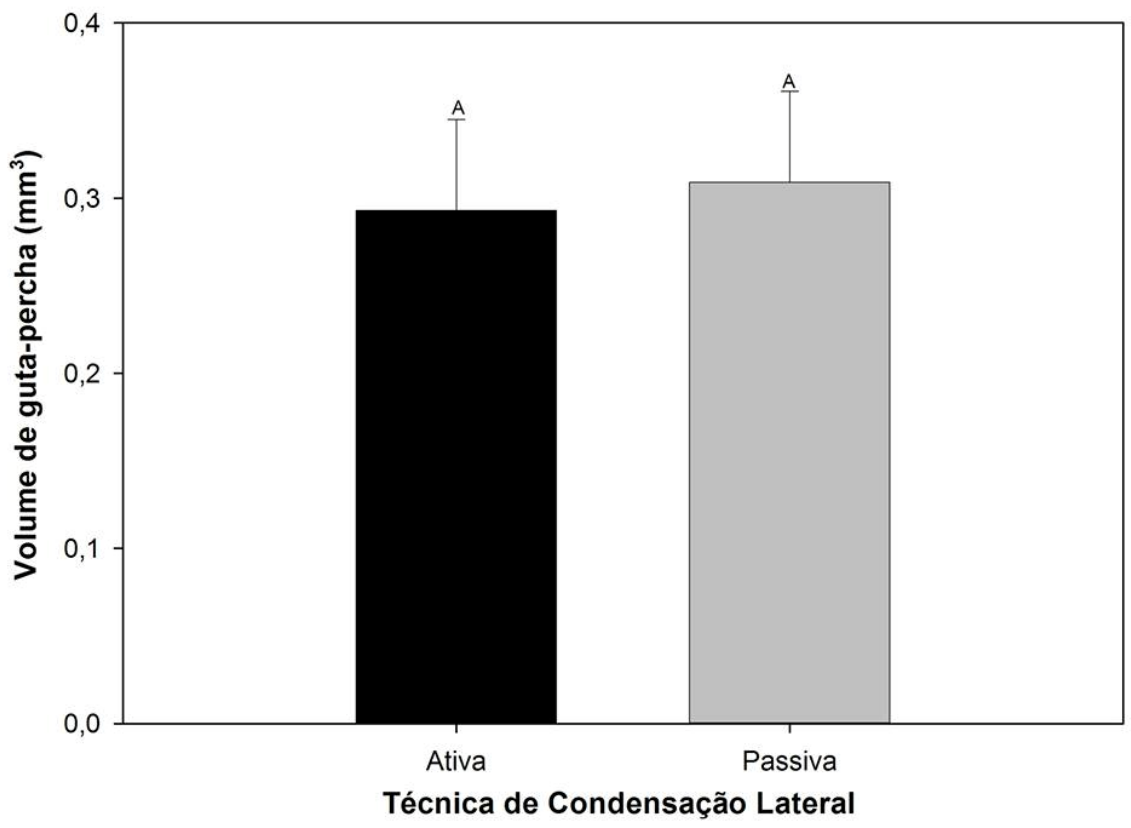

Figura 5. Gráfico esquemático do volume em $\mathrm{mm}^{3}$ de guta-percha no milímetro apical do comprimento de trabalho comparando a técnica de condensação lateral ativa e passiva. 


\section{Volume de cimento endodôntico em relação à massa obturadora total}

A análise de variância para o volume de cimento endodôntico demonstrou haver diferença estatisticamente significante para o fator cimento endodôntico $(p=0,023)$, técnica obturadora $(p<0,001)$ e pelas interações dos fatores $(p=0,015)$ (Tabela 4).

Tabela 4. Análise de Variância a dois critérios para valores de volume de cimento endodôntico no milímetro apical de obturação em relação aos cimentos obturadores e as técnicas de obturação e suas interações.

\begin{tabular}{lccccc}
\hline \multicolumn{1}{c}{ Fator } & GL & $\begin{array}{c}\text { Soma dos } \\
\text { quadrados }\end{array}$ & $\begin{array}{c}\text { Média dos } \\
\text { quadrados }\end{array}$ & $\begin{array}{c}\text { Valor de } \\
\text { F }\end{array}$ & $\begin{array}{c}\text { Valor de } \\
\text { P }\end{array}$ \\
\hline Cimento endodôntico & 3 & 0,00147 & 0,000488 & 4,867 & $0,004^{*}$ \\
$\begin{array}{l}\text { Técnica obturadora } \\
\text { Cimento endodôntico }\end{array}$ & 1 & 0,00201 & 0,00201 & 20,067 & $<0,001^{*}$ \\
Técnica obturadora & 3 & 0,00115 & 0,000382 & 3,809 & $0,015^{*}$ \\
$\begin{array}{l}\text { Residual } \\
\text { Total }\end{array}$ & 56 & 0,00562 & 0,000100 & & \\
${ }^{*}$ Diferença estatisticamente significante entre os grupos $(\mathrm{p}<0,05)$. & & \\
\end{tabular}

${ }^{*}$ Diferença estatisticamente significante entre os grupos $(p<0,05)$.

O teste de Tukey para o fator de variação Cimento endodôntico demonstrou que o grupo obturado com o Sealapex apresentou o menor volume de cimento no milímetro apical do comprimento de trabalho, apresentando diferença estatisticamente significante com os dentes obturados com o AH Plus e Sealer 26 $(p<0,05)$, que tiveram o maior volume de cimento. Resultado intermediário foi obtido pelos dentes obturados com o Endofill (Tabela 5). 
Tabela 5. Médias \pm desvios-padrão do volume de cimento endodôntico em $\mathrm{mm}^{3}$ nos diferentes grupos.

\begin{tabular}{cc}
\hline Cimentos endodônticos & Média Geral \\
\hline AH Plus & $0,112 \pm 0,008 \mathrm{~B}$ \\
Endofill & $0,103 \pm 0,010 \mathrm{AB}$ \\
Sealapex & $0,100 \pm 0,009 \mathrm{~A}$ \\
Sealer 26 & $0,109 \pm 0,018 \mathrm{~B}$
\end{tabular}

${ }^{*}$ Letras diferentes indicam diferença estatística entre os grupos experimentais ao teste de Tukey $(p<0,05)$.

A Figura 6 ilustra o gráfico das médias comparando o volume de cimento endodôntico presente no milímetro apical do comprimento de trabalho entre os cimentos endodônticos.

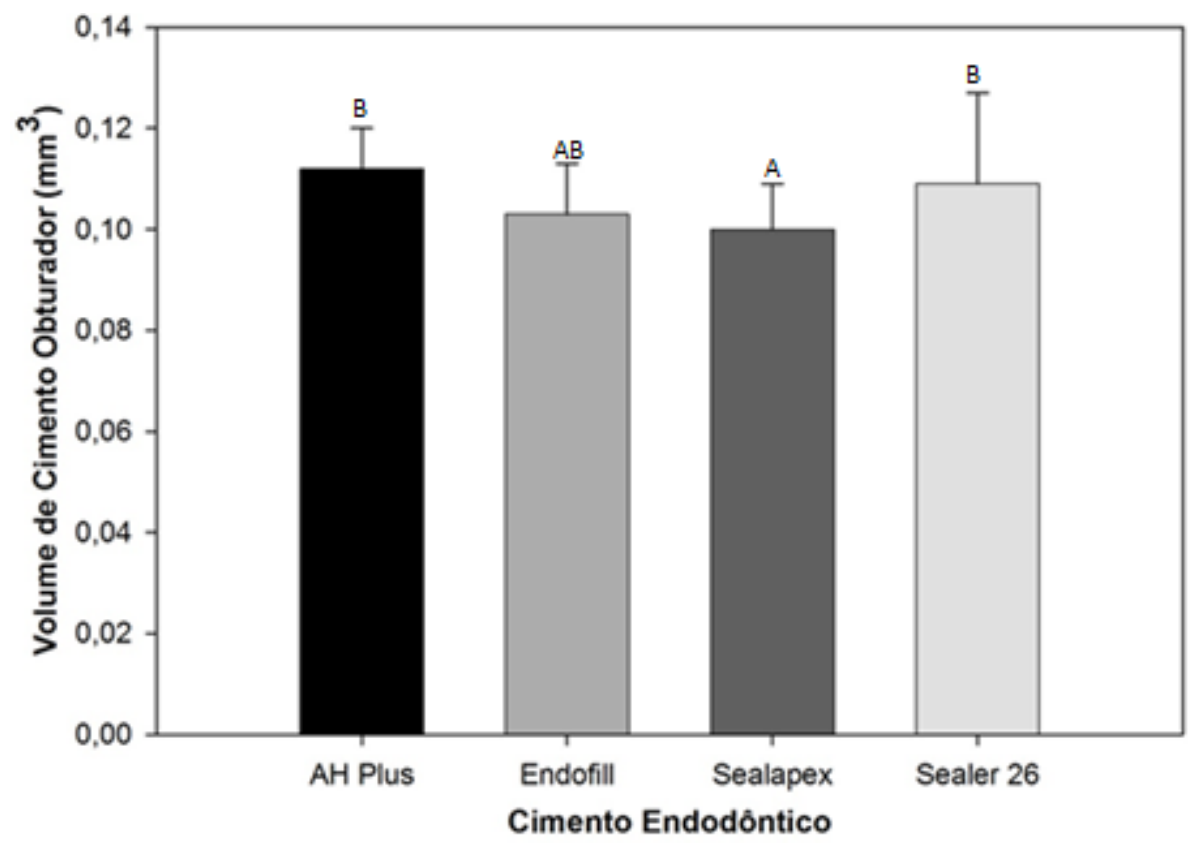

Figura 6. Gráfico esquemático comparando o volume em $\mathrm{mm}^{3}$ do cimento endodôntico no milímetro apical do comprimento de trabalho entre os grupos de cimento estudados.

A Figura 7 ilustra o gráfico representativo do teste de Tukey para o fator de variação Técnica obturadora mostrando a diferença das médias dos valores de volume de cimento obturador no milímetro apical do comprimento de trabalho comparando a técnica de condensação lateral ativa $(0,100 \pm 0,010 \mathrm{~A})$ e passiva $(0,111 \pm 0,012 \mathrm{~B})$, que apresentaram diferença estatisticamente significante entre si $(p<0,001)$. 


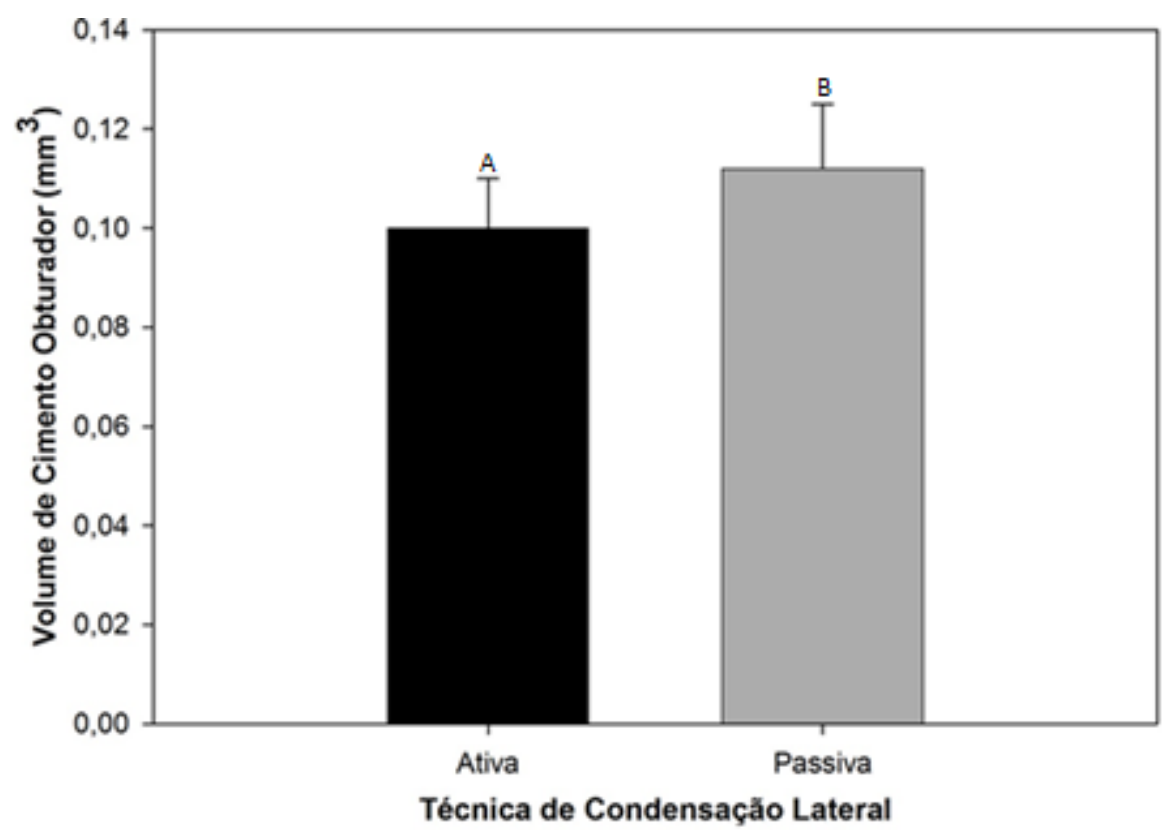

Figura 7. Gráfico esquemático do volume de cimento endodôntico no milímetro apical do comprimento de trabalho comparando a técnica de condensação lateral ativa e passiva.

O teste de Tukey para a interação dos fatores (cimento endodôntico x técnica obturadora) em relação ao volume de cimento endodôntico no milímetro apical do comprimento de trabalho está apresentado na Tabela 6.

Quando comparado o volume de cimento endodôntico entre todos os grupos, não houve diferença estatisticamente significante entre os cimentos obturadores com a técnica de condensação lateral ativa. Já com a técnica de condensação lateral passiva, o grupo do Sealapex apresentou o menor volume de cimento endodôntico, estatisticamente similar ao Endofill. O grupo do Sealer 26 apresentou o maior volume, sendo estatisticamente similar ao AH Plus. Resultados intermediários foram obtidos pelo AH Plus e o Endofill.

Quando comparado o volume de cimento endodôntico de cada grupo entre as técnicas de condensação lateral ativa e passiva, o grupo do Sealer 26 apresentou menores valores de cimento endodôntico no milímetro apical com a técnica de condensação lateral ativa $(p<0,001)$. No entanto, para os demais grupos de cimentos obturadores, não houve diferença estatisticamente significante do volume de cimento endodôntico entre as técnicas de obturação $(p>0,05)$. 
Tabela 6. Teste de Tukey. Fatores de variação: Cimento endodôntico e técnica obturadora. Médias \pm desvios-padrão para volume de cimento.

\begin{tabular}{ccc}
\hline Cimento & \multicolumn{3}{c}{ Técnica } \\
\cline { 2 - 3 } Endodôntico & Passiva & Ativa \\
\hline AH Plus & $0,115 \pm 0,009 \mathrm{Abc}$ & $0,108 \pm 0,005 \mathrm{Aa}$ \\
Endofill & $0,108 \pm 0,008 \mathrm{Aab}$ & $0,099 \pm 0,011 \mathrm{Aa}$ \\
Sealapex & $0,101 \pm 0,005 \mathrm{Aa}$ & $0,098 \pm 0,012 \mathrm{Aa}$ \\
Sealer 26 & $0,122 \pm 0,016 \mathrm{Bc}$ & $0,096 \pm 0,010 \mathrm{Aa}$ \\
\hline
\end{tabular}

* Letras diferentes (letras maiúsculas, comparação entre as colunas para cada técnica de obturação; letra minúscula, comparação entre linhas para os diferentes grupos de cimentos obturadores) indicam diferença estatística entre os grupos experimentais ao teste de Tukey $(p<0,05)$.

A Figura 8 ilustra o gráfico da diferença de médias do volume de cimento endodôntico no milímetro apical comparando as técnicas de condensação lateral ativa e passiva em cada grupo e os cimentos endodônticos com cada técnica.

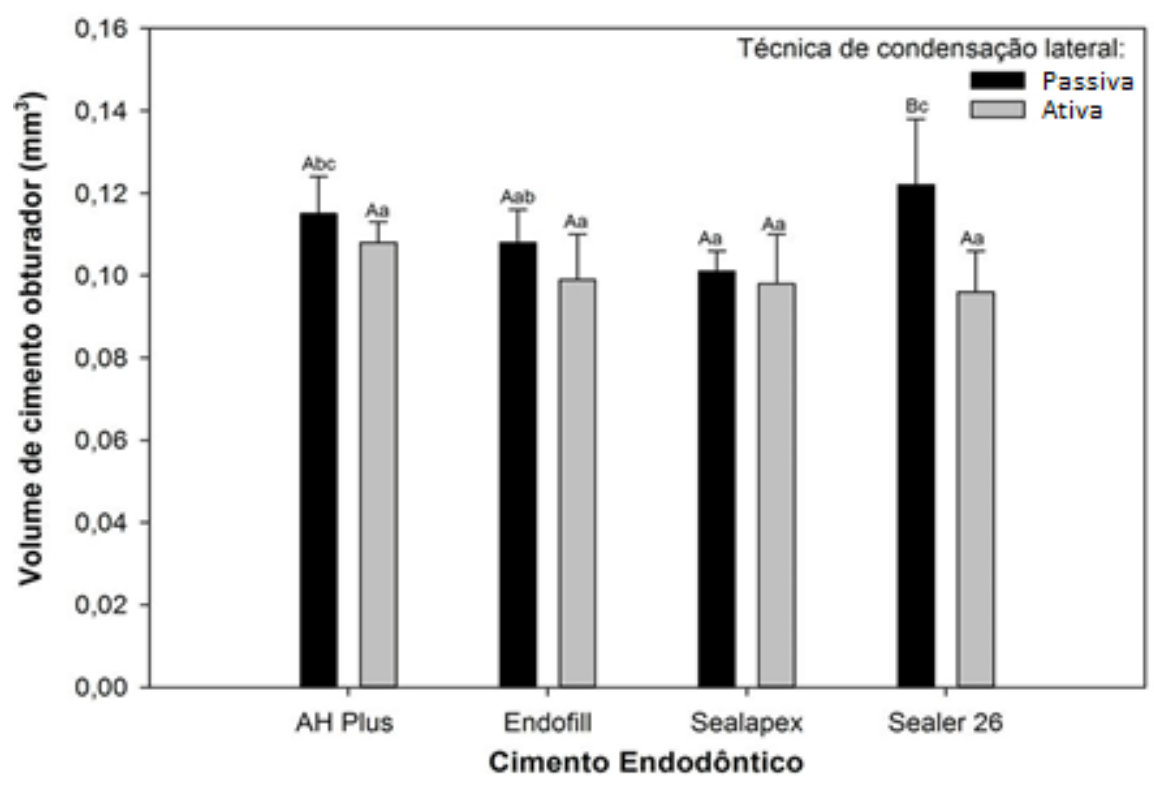

Figura 8. Gráfico esquemático mostrando a distribuição dos volumes de cimento endodôntico entre as técnicas de condensação lateral ativa e passiva dos quatro grupos de cimento endodôntico.

Para fins de ilustração, nas Figuras 9, 10, 11 e 12, estão dispostos os modelos tridimensionais representativos do volume da guta-percha e do cimento no milímetro estudado do comprimento de trabalho, que foi o apical, dos quatro grupos 
analisados. As reconstruções foram feitas com o auxílio da microtomografia computadorizada. A criação do modelo tridimensional foi realizado através do programa CTAn v1.13.5.1+ (Bruker-microCT, Kontich, Bélgica) e a sua visualização pelo CTVol 2.2.3.0 (Bruker-microCT, Kontich, Bélgica). 


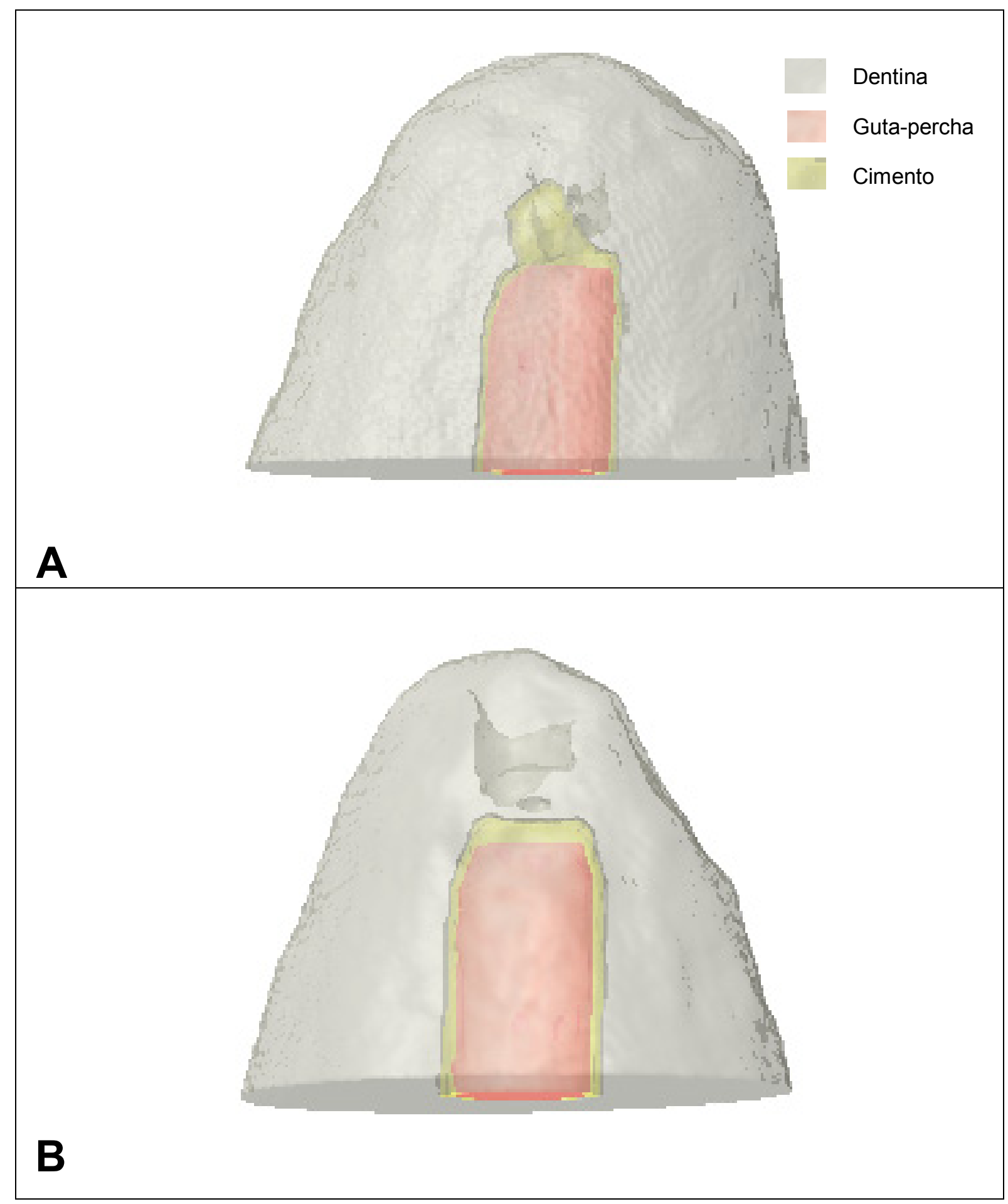

Figura 9. Modelos tridimensionais construídos a partir de imagens obtidas no milímetro apical do grupo do cimento obturador Sealapex. (A) Obturação realizada com a técnica de condensação lateral ativa. (B) Obturação realizada com a técnica de condensação lateral passiva. 


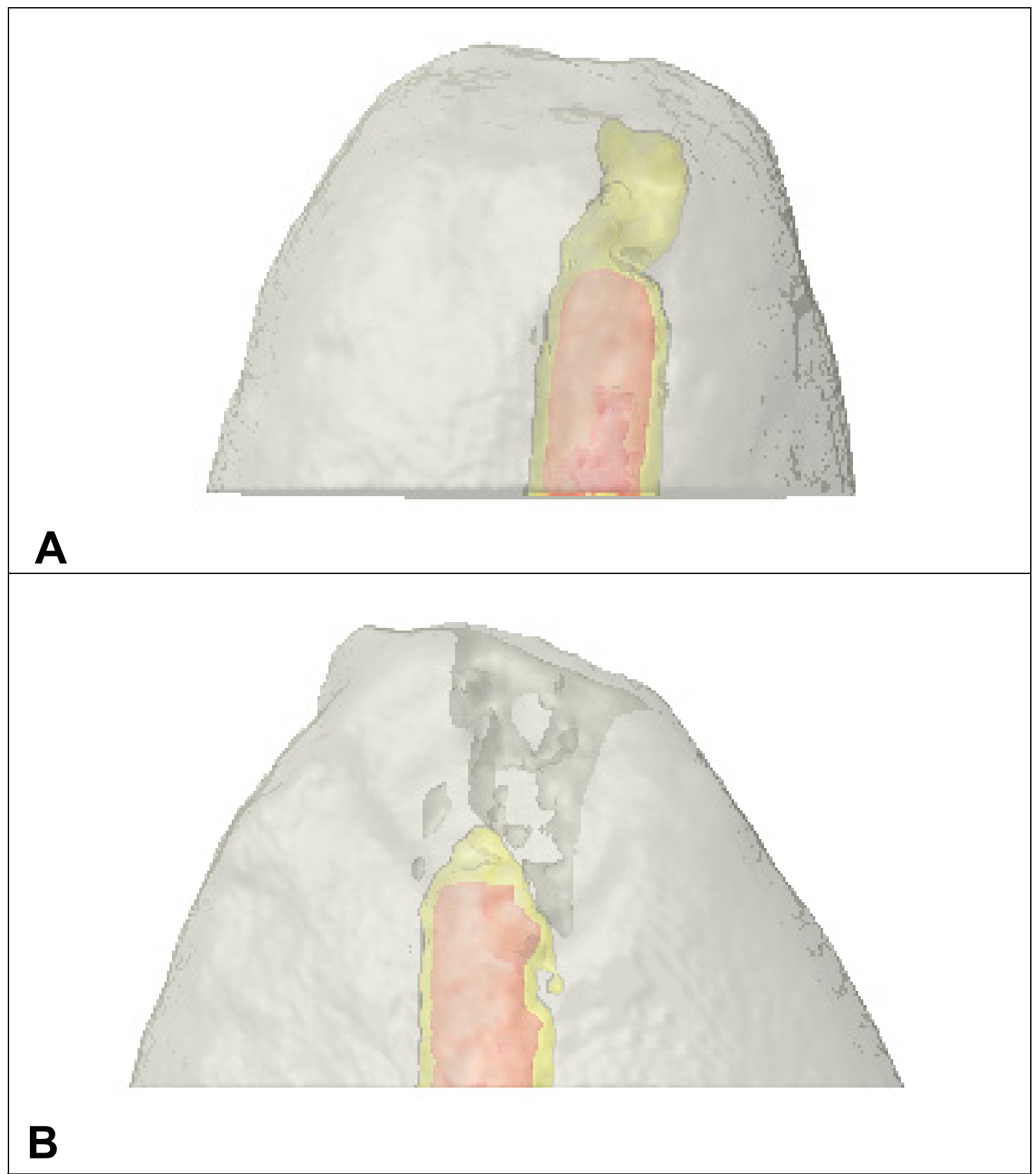

Figura 10. Modelos tridimensionais construídos a partir de imagens obtidas no milímetro apical do grupo do cimento obturador Sealer 26. (A) Obturação realizada com a técnica de condensação lateral ativa. (B) Obturação realizada com a técnica de condensação lateral passiva. 


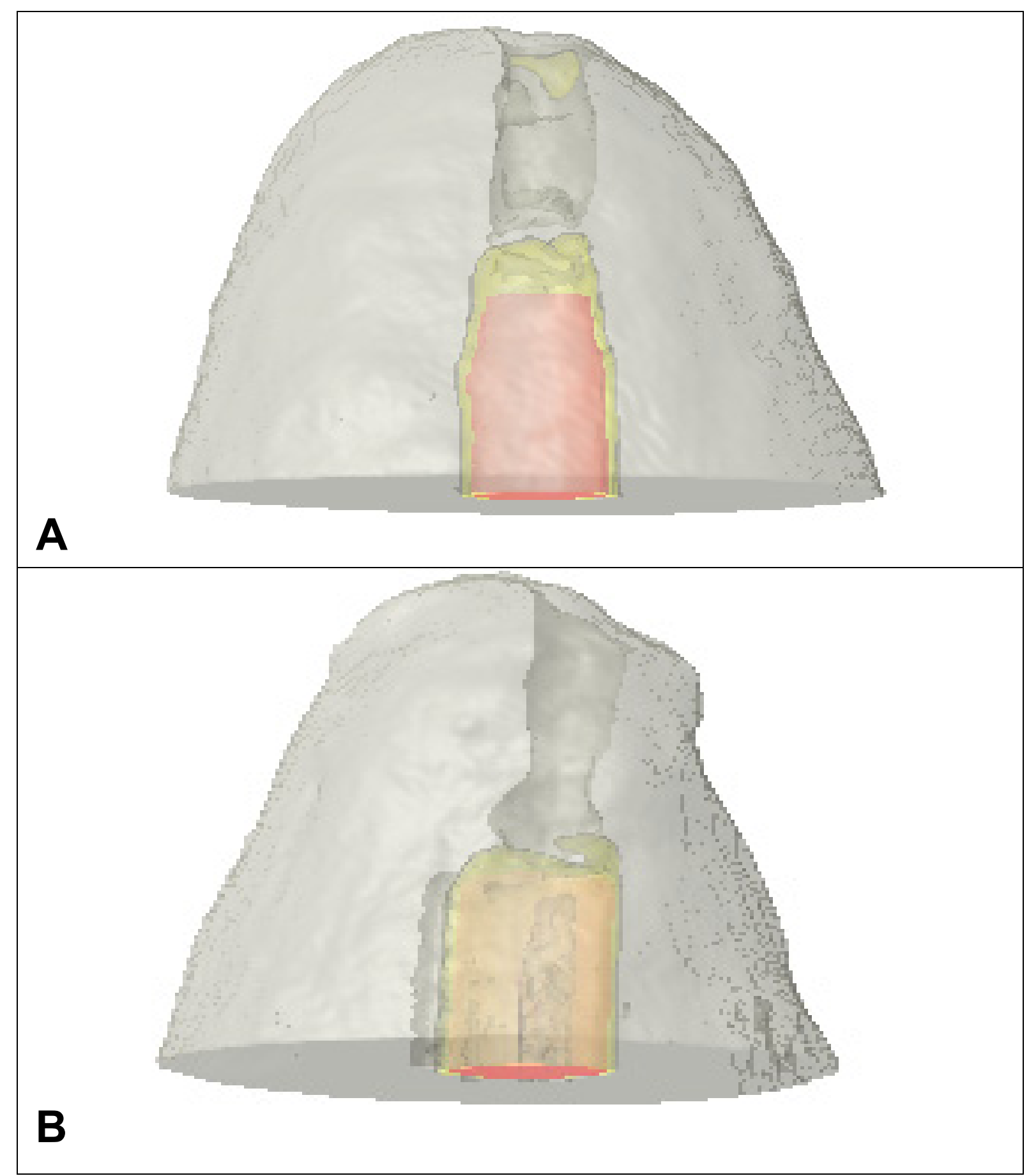

Figura 11. Modelos tridimensionais construídos a partir de imagens obtidas no milímetro apical do grupo do cimento obturador AH Plus. (A) Obturação realizada com a técnica de condensação lateral ativa. (B) Obturação realizada com a técnica de condensação lateral passiva. 


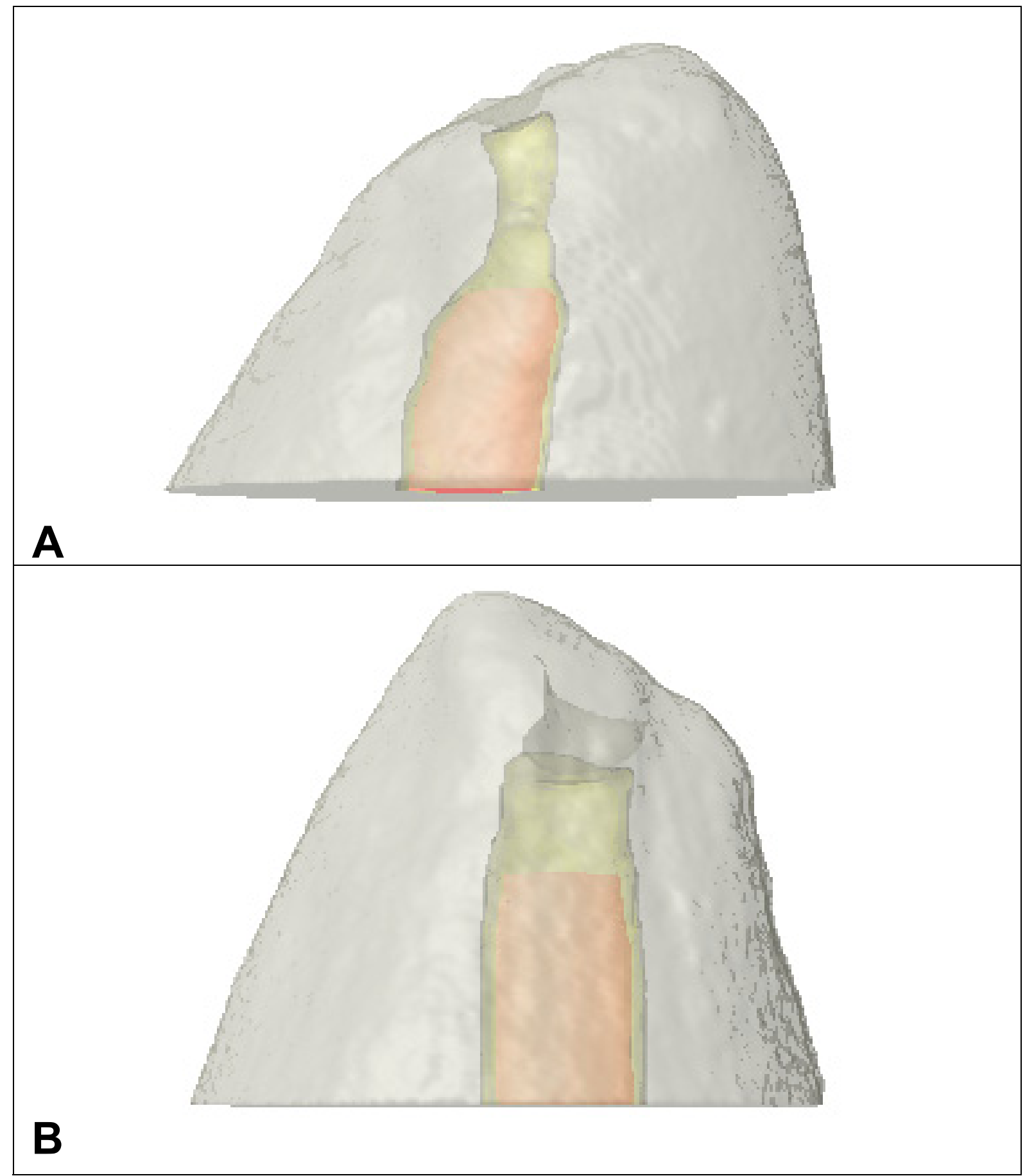

Figura 12. Modelos tridimensionais construídos a partir de imagens obtidas no milímetro apical do grupo do cimento obturador Endofill. (A) Obturação realizada com a técnica de condensação lateral ativa. (B) Obturação realizada com a técnica de condensação lateral passiva. 


\section{Discussão}



O sucesso de um tratamento endodôntico pode ser comprometido se o sistema de canais radiculares não for adequadamente obturado, mesmo com um ambiente limpo e bem preparado, principalmente em seu terço apical (GULSAHI et al., 2007a). A função da obturação é selar o SCR, impossibilitando a entrada de microorganismos e seus produtos tóxicos nos tecidos periapicais (RESENDE et al., 2009). SCHILDER (1967) sugeriu que o material de obturação do canal radicular ideal deve ser bem adaptado às paredes do SCR e às suas irregularidades, e que todo o comprimento do canal seja densamente compactado com uma massa homogênea de guta-percha. Assim, a quantidade de cimento deve ser minimizada, enquanto a quantidade de material sólido, a guta-percha, deve ser maximizada (GORDON; LOVE; CHANDLER, 2005; EPLEY et al., 2006), motivo pelos quais são realizados estudos que têm por objetivo avaliar a presença de guta-percha (SILVAFILHO et al., 2013) e de cimento endodôntico na massa obturadora, como no presente caso, até mesmo como indicador indireto da quantidade de obturações bem compactadas.

A qualidade da obturação do canal radicular no terço apical é importante (LUCCY; WELLER; KULILD, 1990), e assumindo que a espessura mínima de cimento endodôntico e menos espaços vazios são boas medidas de capacidade de selamento a longo prazo (GULSABI et al., 2007), este estudo quantificou o volume de cimento obturador e guta-percha nas obturações.

Em geral, a técnica da condensação lateral é relativamente simples de executar regularmente em canais cônicos (DE-DEUS et al., 2008). Dentes anteriores superiores foram escolhidos, devido ao seu grande diâmetro do canal, facilitando a maior quantidade total de material obturador no SCR (JAMES et al., 2007), permitindo assim que todas as variações fossem mais facilmente notadas. As coroas 
foram deixadas intactas e as cirurgias de acesso ideal foram feitas em cada dente, simulando as condições clínicas e aumentando assim a validade dos resultados.

Uma grande variedade de cimento obturador encontra-se disponível no mercado. Os cimentos à base de óxido de zinco e eugenol vêm sendo usado por muitas décadas devido às suas propriedades físico-químicas satisfatórias, como sua plasticidade, tempo de presa lento na ausência de umidade e pequena mudança volumétrica. Como também os cimentos à base de resina epóxica que apresentam excelente selamento apical, fornecem solubilidade reduzida, microretenção à dentina e uma baixa sensibilidade à umidade, destacando-se o cimento AH Plus. Além dos cimentos contendo hidróxido de cálcio, que já mostraram sua eficácia quanto à ação antimicrobiana e sua biocompatibilidade tecidual (DE ALMEIDA et al., 2000; VENTURI, 2008). Portanto foram escolhidos para este estudo os cimentos que representassem as várias opções disponíveis para o uso clínico de acordo com a sua composição, sendo eles: Endofill (Cimentos à base de óxido de zinco e eugenol), Sealapex (contendo hidróxido de cálcio), Sealer 26 e AH Plus (à base de resina époxica).

A condensação lateral a frio é a técnica de obturação mais frequentemente ensinada nas Universidades e praticada pelos profissionais mundialmente, provavelmente devido à relação custo-eficiência, pela segurança de execução e controle do comprimento do canal durante o procedimento da obturação, diminuindo o risco de sobreobturação do canal radicular, pela simplicidade de execução, adaptabilidade à maioria dos casos, além de não requerer equipamentos caros. Mesmo com o desenvolvimento de várias outras técnicas de obturação a condensação lateral ainda representa o padrão e continua sendo usada com uma 
grande frequência (GULSAHI et al., 2007; DE-DEUS et al., 2008; PETERS; SONNTAG; PETERS, 2010), motivo pelo qual foi escolhida neste trabalho.

A lógica da técnica de condensação lateral é aumentar a proporção de gutapercha no canal, que é dimensionalmente estável, em relação à de cimento, com o objetivo de diminuir potencialmente as lacunas que possam ocorrer devido à contração ou mesmo a dissolução do cimento, especialmente na região apical (GULSAHI et al., 2007; SOUZA et al., 2009), apesar de serem os cimentos os responsáveis pelas principais funções biológicas da obturação, sendo elas o selamento do sistema de canais radiculares, sepultamento das bactérias remanescentes e o preenchimento das irregularidades no canal preparado (ØRSTAVIK, 2005).

Guta-percha tem sido o material de escolha para obturação do canal há quase 150 anos e é bem aceito pela comunidade acadêmica como o material de obturação padrão (JAMES et al., 2007). Assim, a porcentagem de guta-percha vem sendo usada como uma medida de qualidade da obturação (JARRET et al., 2004). Segundo SOUZA et al. (2009), em termos gerais as técnicas de compactação de guta-percha são preferíveis, pois maximizam o volume de guta-percha, resultando numa fina camada de cimento nas paredes dos canais radiculares. Portanto, foram utilizadas neste estudo as técnicas de condensação lateral ativa e passiva no intuito de verificar o volume de guta-percha e de cimento endodôntico no milímetro apical das obturações.

A microtomografia computadorizada surgiu como uma técnica não invasiva que permite a avaliação precisa das características morfológicas, a qualidade de instrumentação e obturação do SCR tridimensionalmente, sendo considerada atualmente como padrão ouro em estudos ex vivo (IKRAM et al., 2009; MOORE; 
FITZ-WALTER; PARASHOS, 2009; VIER-PELISSER et al., 2010; PETERS, PAQUÉ, 2011; GANDOLFI et al., 2013). Permite calcular área e volume das amostras, avaliar qualitativamente e quantitativamente as imagens em 3D ou em múltiplos planos e discriminar os componentes da obturação, cimento endodôntico e guta-percha (RHODES et al., 1999; JUNG; LOMMEL; KLIMEK, 2005), bem como a reprodutibilidade dos resultados. É passível de comparação com estudos histológicos (NASERI et al., 2013). Devido a esse conjunto de características, a micotomografia foi utilizada no presente estudo para analisar tridimensionalmente a obturação do SCR, com a avaliação dos volumes de cimento e de guta-percha.

De acordo com os achados no presente estudo, quando comparadas as técnicas de condensação lateral ativa e passiva, apenas o grupo do cimento Sealer 26 apresentou-se com maior volume de cimento na técnica passiva em relação à ativa. Já quando comparados os cimentos, não foi encontrada diferença entre eles com a técnica de condensação lateral ativa. Porém, com a técnica de condensação lateral passiva, o grupo do Sealapex apresentou o menor volume de cimento endodôntico, similar ao Endofill. Os grupos dos dentes obturados pelo Sealer 26 e AH Plus apresentaram os maiores volumes, cujo resultado pode ser explicado pela maior viscosidade dos cimentos à base de resina epóxica (VENTURI, 2008).

Fluidez adequada e espessura fina da película são aspectos do cimento obturador, necessários para a satisfatória distribuição do vedante sobre as irregularidades anatômicas (MARCIANO et al., 2011). Neste estudo, observou-se a presença de uma camada de película do cimento mais fina na técnica de condensação lateral ativa do que na passiva, visto que são usados os espaçadores digitais na técnica ativa, com o objetivo de criar espaços para maior introdução de guta-percha na obturação, diminuindo assim os espaços vazios, que ocorrem devido 
a contração ou dissolução do cimento obturador e também pelo não preenchimento de todas as irregularidades. Alguns autores também encontraram resultados semelhantes, onde a guta-percha ocupou maior quantidade da obturação quando utilizada a técnica da condensação lateral ativa, em comparação com a técnica de cone único e sem a condensação lateral, nos $2 \mathrm{~mm}$ apicais aquém do ápice (JARRET et al., 2004; GORDON; LOVE; CHANDLER, 2005).

DE ALMEIDA et al. (2000) observaram que o melhor selamento apical foi obtido com o $\mathrm{AH}$ Plus, que é um cimento à base de resina epóxica, derivado do $\mathrm{AH}$ 26, quando comparado a uma base de óxido de zinco e eugenol (Fill Canal) e um à base de ionômero de vidro (Ketac Endo). Já COBANKARA et al. (2006) mostraram em seu estudo que o melhor selamento apical foi encontrado nos grupos obturados pelo cimento Sealapex, quando comparado ao AH Plus e ao Rocanal 2. Acredita-se que o menor volume de cimento seja responsável pelo melhor selamento, dessa forma, especula-se, neste trabalho, um melhor selamento no milímetro apical de trabalho com o cimento Sealapex, similar ao Endofill quando comparado com o $\mathrm{AH}$ Plus e o Sealer 26, devido ao menor volume de cimento endodôntico encontrado no primeiro. A razão para discrepância nos resultados encontrados nestes estudos em relação aos outros pode ser explicada pelo fato de serem utilizadas diferentes metodologias.

Outra razão para o menor volume de cimento endodôntico no milímetro apical que foi observado com o cimento endodôntico Sealapex pode ser devida ao melhor escoamento em relação aos outros cimentos endodônticos estudados. Segundo HOSOYA et al. (2004) isso pode ser explicado devido à presença do reagente $\mathrm{Ca}(\mathrm{OH})^{2}$ que diminue o escoamento, ocasionado pelas interações químicas. Em seu estudo foram testados quatro cimentos endodônticos contendo hidróxido de cálcio, 
dentre eles o Sealapex, e para o teste de escoamento foi adicionado reagentes $\mathrm{Ca}(\mathrm{OH})^{2}$ e então observado o desempenho dos cimentos endodônticos, resultando assim na diminuição do escoamento em todos os grupos de cimentos endodônticos, porém essas interações químicas que provocam tal fato são desconhecidas. SCELZA et al. (2006) também estudaram as propriedades físico-químicas, mostrando que em relação ao escoamento o Endofill e o Sealapex apresentaram os maiores valores, seguido do $\mathrm{AH}$ Plus e por último o Sealer 26, que apresentou menor valor. FARIA-JÚNIOR et al. (2010) observaram em seu estudo que o Sealapex alcançou o melhor escoamento, porém não apresentou diferença com o AH Plus.

A viscosidade dos cimentos está relacionada ao escoamento, pois se os cimentos apresentarem baixa viscosidade inicial terão um melhor escoamento entre os cones e as paredes do canal radicular. O escoamento dos cimentos endodônticos é uma importante propriedade, que pode determinar a eficiência das obturações do sistema de canais radiculares, de suas irregularidades anatômicas e dos espaços entre o cone principal e os cones acessórios. Porém, o escoamento elevado pode resultar em extrusão apical, podendo lesionar os tecidos periapicais quando citotóxico. No caso dos cimentos com boa compatibilidade, a extrusão pode ser mais favorável (BRANSTETTER; VON FRAUNHOFER, 1982; ZHOU et al., 2013).

Neste estudo, avaliaram-se os volumes dos componentes da massa obturadora (guta-percha e cimento) separadamente devido à complexidade anatômica existente no modelo experimental utilizado na pesquisa -dentes naturaispois da análise do volume de guta-percha não deflui naturalmente do volume do cimento, já que, se assim o fosse, estar-se-ía diante da hipótese ideal, em que estabelecido o volume do canal e da guta-percha, pela simples operação de 
subtração, ter-se-ía o volume do cimento. Isso somente seria verdade diante de algumas circunstâncias, a saber: a de que o canal fosse um cone perfeito, de que a determinação exata do seu volume fosse fácil e possível e, ao final, de que estivesse hermeticamente obturado. Nenhuma das hipóteses adentra na realidade clínica, o que motivou as análises realizadas separadamente.

Novos estudos, com inovações tecnológicas devem ser realizados com o intuito de se pesquisarem os materiais obturadores já existentes e outros novos, de modo a melhorar a eficiência dessa etapa operatória e obter melhores índices de sucesso clínico da terapia endodôntica. 



\section{Conclusão}



De acordo com os resultados obtidos nesse estudo, pode-se concluir que:

1- Em relação ao volume de guta-percha presente na massa obturadora dos canais radiculares, não houve influência das técnicas de condensação lateral ativa e passiva.

2- A obturação dos canais radiculares com Sealer 26 proporcionou maior volume de guta-percha na massa obturadora, semelhante ao AH Plus e Sealapex.

3- Quanto ao volume de cimento obturador presente na massa, o grupo obturado com o Sealapex apresentou menor volume de cimento endodôntico, semelhante ao Endofill.

4- A técnica de condensação lateral ativa apresentou menor valor de volume de cimento do que a passiva. 



\section{Referências Bibliográficas}



ARI, H.; BELLI, S.; GUNES, B. Sealing ability of Hybrid Root SEAL (MetaSEAL) in conjunction with different obturation techniques. Oral Surgery Oral Medicine Oral Pathology Oral Radiology Endodontics, v.109, n.6, p.e113-e116, 2010.

BORGES, R. P.; SOUSA-NETO, M. D.; VERSIANI, M. A.; RACHED-JÚNIOR, F. A.; DE-DEUS, G.; MIRANDA, C. E. S.; PÉCORA, J. D. Changes in the surface of four calcium silicate-containing endodontic materials and an epoxy resin-based sealer after a solubility test. International Endodontic Journal, v.45, n.5, p.419-428, 2012.

BRANSTETTER, J.; VON FRAUNHOFER, J. A. The physical properties and sealing action of endodontic sealer cements: a review of the literature. Journal of Endodontics, v.8, n.7, p.312-316, 1982.

CALLAHAN, J. R. Rosin solution for the sealing of dentinal tubule and as na adjuvant in the filling of root canals. Dental Cosmos, v.56, n.12, p.1376, 1914.

CECCHIN, D.; SOUZA, M.; CARLINI-JÚNIOR, B.; BARBIZAM, J. V. B. Bond strenght of Resilon/ Epiphany compared with gutta-percha and sealers Selaer 26 and Endo Fill. Australian Endodontic Journal, v.38, n.1, p.21-25, 2012.

CHANDRASEKHAR, V.; MORISHETTY, P. K.; METLA, S. L.; RAJU, C. Expansion of gutta-percha in contact with various concentrations of zinc oxide-eugenol sealer: a three-dimensional volumetric study. Journal of Endodontics, v.37, n.5, p. 697-700, 2011.

CHENG, Y.; HUANG, S.; HSIEN, H.;CHIANG, Y.; LIN, C. Influence of cyclic heating on physical property and biocompatibility of $\alpha$ - and $\beta$ - form gutta-percha. Journal of the Formosan Medical Association, v.xx, p.1-8, 2012.

COBANKARA, F. K.; ORUCOGLU, H.; SENGUN, A.;BELLI, S. The quantitative evaluation of apical sealing of four endodontic sealers. Journal of Endodontics, v.32, n.1, p.66-68, 2006.

COLLINS, J. B. S.; WALKER, M. P.; KULILD, J.; LEE, C. A comparison of three gutta-percha obturation techniques to replicate canal irregularities. Journal of Endodontics, v.32, n.8, p.762-765, 2006.

DE ALMEIDA, W. A.; LEONARDO, M. R.; TANOMARU FILHO, M.; SILVA, L. A. B. Evaluation of apical sealing of three endodontic sealers. Internacional Endodontic Journal, v.33, n.1, p.25-27, 2000.

DE-DEUS, G.; REIS, C.; BEZNOS, D.; ABRANCHES, A. M. G.; COUTINHO-FILHO, T.; PACIORNIK, S. Limited ability of three commonly used thermoplasticized guttapercha techniques in filling oval-shaped canals. Journal of Endodontics, v.34, n.11, p.1401-1405, 2008.

DEITCH, A. K.; LIEWEHR, F. R.; WEST, L. A.; PATTON, W. R. A comparison of fill density obtained by supplementing cold lateral condensation with ultrassonic condensation. Journal of Endodontics, v.28, n.8, p.665-667, 2002. 
DOWKER, S. E.; DAVIS, G. R.; ELLIOTT, J. C. X-ray microtomography: nondestructive three-dimensional imaging for in vitro endodontic studies. Oral Surgery Oral Medicine Oral Pathology Oral Radiology Endodontics, v.83, n.4, p. 510-516, 1997.

EPLEY, S. R.; FLEISCHMAN, J; HARTWELL, G.; CICALESE, C. Completeness of root canal obturations: epiphany techniques versus gutta-percha techniques. Journal of Endodontics, v.32, n.6, p.541-544, 2006.

FARIA-JÚNIOR, N. B.; MASSI, S.; CROTI, H. R.; GUTIERREZ, J. C. R.; DAMETTO, F. R.; VAZ, L. G. Comparative assessment of the flow rate of root canal sealers. Journal of Dental Science, v.25, n.2, p.170-173, 2010.

FLORES, D. S. H.; RACHED-JUNIOR, F. J. A.; VERSIANI, M. A.; GUEDES, D. F. C.; SOUSA-NETO, M. D.; PÉCORA, J. D. Evaluation of physicochemical properties of four root canal sealers. Internacional Endodontic Journal, v.44, n.2, p.126-135, 2011.

GANDOLFI, M. G.; PARRILLI, A. P.; FINI, M.; PRATI, C.;DUMMER, P. M. H. 3D micro-CT analysis of the interface voids associates with Thermafill root fillings used with $\mathrm{AH}$ Plus or a flowable MTA sealer. Internacional Endodontic Journal, v.46, n.3, p.253-263, 2013.

GARRIDO, A. D. B.; LIA, R. C. C.; FRANÇA, S. C.; DA SILVA, J. F., ASTOLFIFILHO, S.; SOUSA-NETO, M. D. Laboratory evaluation of the physicochemical properties of a new root canal sealer based on Copaifera multijuga oil-resin. International Endodontic Journal, v.43, n.4, p.283-291, 2010.

GILLEN, B. M.; LOONEY, S. W.; GU, L. S.; LOUSHINE, B. A.;WELLER, R. N.; LOUSHINE, R. J.;PASHLEY, D. H.;TAY, F. R. Impact of the quality of coronal restoration versus the quality of root canal fillings on sucess of root canal treatment: a systematic review and meta-analysis. Journal of Endodontics, v.37, n.7, p.895902, 2011.

GORDON, M. P. J.; LOVE, R. M.; CHANDLER, N. P. An evoluation of .06 tapered gutta-percha cones for filling of .06 taper prepared curved root canals. Internacional Endodontic Journal, v.38, n.2, p.87-96, 2005.

GROSSMAN, L. An improved root canal cement. Journal American Dental Association, v.56, n.3, p.381-385, 1958.

GULSAHI, K.; CEHRELI, Z. C.; KURANER, T.; DAGLI, F. T. Sealer area associated with cold lateral condensation of gutta-percha and warm coated carrier filling systems in canals prepared with various Rotary $\mathrm{NiTi}$ systems. Internacional Endodontic Journal, v.40, n.4, p.275-281, 2007.

GULSAHI, K.; CENHELI, Z. C.; ONAY, E. O.;TASMAN-DAGLI, F.; UNGOR, M. Comparison of the area of resin-based sealer and voids in roots obturated with resilon and gutta-percha. Journal of Endodontics, v.33, n.11, p.1338-1341, 2007a. 
HOSOYA, N.; KURAYAMA, H; LINO, F.; ARAI, T. Effects of calcium hydroxide on physical and sealing properties of canal sealers. Internacional Endodontic Journal, v.37, n.3, p.178-184, 2004.

IKRAM, O. H.; PATEL, S.; SAURO, S.; MANNOCCI, F. Micro-computed tomography of tooth tissue volume changes following endodontic procedures and post space preparation. Internacional Endodontic Journal, v.42, n.12, p.1071-1076, 2009.

JAMES, B. L.; BROWN, C. R., LEGAN, J.J., MOORE, B. K.; VAIL, M. M. An in vitro evaluation of the contents of root canals obturated with gutta percha and $\mathrm{AH}-26$ sealer or resilon and epiphany sealer. Journal of Endodontics, v.33, n.11, p.13591363, 2007.

JARRET, I. S.; MARX, D.; COVEY, D.; KARMAZIN, D.; LAVIN, M.; GOUND, T. Percentage of canals filled in apical cross sections - an in vitro study of seven obturation techniques. Oral Surgery Oral Medicine Oral Pathology Oral Radiology Endodontics, v.37, n.6, p.392-398, 2004.

JUNG, M.; LOMMEL, D.; KLIMEK, J. The imaging of root canal obturation using micro-CT. Internacional Endodontic Journal, v.38, n.9, p.617-626, 2005.

LEA, C. S.; APICELLA, M. J.; MINES, P.; YANCICH, P.; PARKER, M. H. Comparison of the obturation density of cold lateral compaction versus warm vertical compaction using the continuous wave of condensation technique. Journal of Endodontics, v.31, n.1, p.37-39, 2005.

LUCCY, C. T.; WELLER, R. N.; KULILD, J. C. An evaluation of the apical seal produced by lateral and warm lateral condensation techniques. Journal of Endodontics, v.16, n.4, p.170-172, 1990.

MARCIANO, M. A.; GUIMARÃES, B. M.; ORDINOLA-ZAPATA, R.; BRAMANTE, C. M.; CAVENAGO, B. C.; GARCIA, R. B.; BERNARDINELI, N.; ANDRADE, F. B.; MORAES, I. G.; DUARTE, M. A. H. Physical properties and interfacial adaptation of three epoxy resin-based sealers. Journal of Endodontics, v.37, n.10, p.1417-1421, 2011.

MINER, M. R.; BERZINS, D. W.; BABCALL, J. K. A comparison of termal properties between gutta-percha and a synthetic polymer based root canal filling material (resilon). Journal of Endodontics, v.32, n.7, p.683-6, 2006.

MOORE, J.; FITZ-WALTER, P.; PARASHOS, P. A micro-computed tomographic evaluation of apical root canal preparation using three instrumentation techniques. Internacional Endodontic Journal, v.42, n.12, p.1057-1064, 2009.

NAGASAWA, S.; YOSHIDA, T.; TAMURA, K.; YAMAZOE, M.; HAYANO, K.; ARAI, Y.; YAMADA, H.; KASAHARA, E.; ITO, M. Construction of database for threedimensional human tooth models and its ability for education and research - Carious tooth models. Dental Materials Journal, v.29, n.2, p.132-137, 2010. 
NASERI, M.; KANGARLOU, A.; KHAVID, A.; GOODINI, M. Evaluation of the quality of four root canal obturation techniques using micro-computed tomography. Iranian Endodontic Journal, v.8, n.3, p.89-93, 2013.

NIELSEN, R. B.; ALYASSIN, A. M.; PETERS, D. D.; CARNES, D. L.; LANCASTER, J. Microcomputed tomography: An advanced system for detailed endodontic research. Journal of Endodontics, v.21, n.11, p.561-568, 1995.

NIELSEN, B. A.; BAUMGARTNER, J. C. Spreader penetration during lateral compaction of resilon an gutta-percha. Journal of Endodontics, v.32, n.1, p.52-54, 2006.

ORDINOLA-ZAPATA, R.; BRAMANTE, C. M.; GRAEFF, M. S. Z.; PEROCHENA, A. C.; VIVAN, R. R.; CAMARGO, E. J.; GARCIA, R. B.; BERNARDINELI, N.; GUTMANN, J. L.; MORAES, I. G. Depth and percentage of penetration of endodontic sealers into dentinal tubules after root canal obturation using a lateral compaction technique: A confocal laser scanning microscopy study. Oral Surgery Oral Medicine Oral Pathology Oral Radiology Endodontics, v.108, n.3, p.450-457, 2009.

$\varnothing R S T A V I K$, D. Materials used for root canal obturation: technical, biological and clinical testing. Endodontic Topics, v.12, n.1, p.25-38, 2005.

PABLO, O. V.; ESTEVEZ, R.; SÁNCHEZ, M. P.; HEILBORN, C.; COHENCA, N. Root anatomy and canal configuration of the permanent mandibular first molar: A systematic review. Journal of Endodontics, v.36, n.12, p.1919-1931, 2010.

PETERS, O. A.; BOESSLER, C.; PAQUÉ, F. Root canal preparation with a novel nickel-titanium instrument evaluated with micro-computed tomography: canal surface preparation over time. Journal of Endodontics, v.36, n.6, p.1068-1072, 2010.

PETERS, C. I.; SONNTAG, D.; PETERS, O. A. Homogeneity of root canal fillings performed by undergraduate students with warm vertical and cold lateral techniques. Oral Surgery Oral Medicine Oral Pathology Oral Radiology Endodontics, v.110, n.3, p.41-49, 2010.

PETERS, O. A.; PAQUÉ, F. Root Canal Preparation of Maxillary Molars With the Self-adjusting File: A Micro-computed Tomography Study. Journal of Endodontics, v.37, n.1, p.53-57, 2011.

PLOTINO, G.;GRANDE, N. M.; PECCI, R.; BEDINI, R.; PAMEIJER, C. H.; SOMMA, $F$. Three-dimensional imaging using microcomputed tomography for studying tooth macromorphology. Journal American Dental Association, v.137, n.11, p.15551561, 2006.

RESENDE, L. M.; RACHED-JUNIOR, F. J.; VERSIANI, M. A.; SOUZA-GABRIEL, A. E.; MIRANDA, C. E. S.; SILVA-SOUSA, Y. T. C.; SOUSA NETO, M. D. A comparative study of physicochemical properties of AH Plus, Epiphany, and Epiphany SE root canal sealers. Internacional Endodontic Journal, v.42, n.9, p.785-793, 2009. 
RHODES, J. S.; PITT FORD, T. R.; LYNCH, J. A.; LIEPINS, P. J.; CURTIS, R. V. Micro-computed tomography: a new tool for experimental endodontology. Internacional Endodontic Journal, v.32, n.3, p.165-170, 1999.

SAATCHI, M.; ETESAMI, L. Comparison of spreader penetration during lateral compaction of 0.04 and 0.02 tapered guta-percha master cones. Journal of Dentistry, v.3, n.3, p.112-116, 2006.

SCELZA, M. F. Z.; SCELZA, P.; COSTA, R. F.; CÂMARA, A. Comparative study the physical properties of flow, solubility and disintegration of some root canal sealers. Pesquisa Brasileira em Odontopediatria e Clínica Integrada, v.6, n.3, p.243-247, 2006.

SCHAMBACH, S. J.; BAG, S.; SCHILLING, L.; GRODEN, C.; BROCKMANN, M. A. Application of micro-CT in small animal imaging. Methods, v.50, n.1, p.2-13, 2010.

SCHÄFER, E.; ZANDBIGLARI, T. Solubility of root-canal sealers in water and artificial saliva. Internacional Endodontic Journal, v.36, n.10, p.660-669, 2003.

SCHILDER, H. Filling root canals in three dimensions. Journal of Endodontics, v.11, n.5, p.723-744, 1967.

SILVA, E. J. N. L.; ROSA, T. P.; HERRERA, D. R.; JACINTO, R. C.; GOMES, B. P. F. A.; ZAIA, A. A. Evaluation of cytotoxicity and physicochemical properties of calcium silicate-based endodontic sealer MTA fillapex. Journal of Endodontics, v.39, n.2, p.274-277, 2013.

SILVA-FILHO, J. M.; SOUZA-GABRIEL, A. E.; LEONI, G. B.; DE-BEM, S. H. C.; ALFREDO, E.; SILVA, R. G. Comparison of two techniques for selection of master gutta-percha cone using micro-computed tomography. Brazilian Dental Journal, v.24, n.4, p.367-370, 2013.

SOMMA, F.; CRETELLA, G.; CAROTENUTO, M.; PECCI, R.; BEDINI, R.; DE BIASI, M.; ANGERAME, D. Quality of thermoplasticized and single point root fillings assessed by micro-computed tomography. Internacional Endodontic Journal, v.43, n.2, p.1122-1131, 2011.

SOUZA, E. M.; WU, M-K.; VAN DER SLUIS, L. W.; LEONARDO, R. T.; BONETTIFILHO, I.; WESSELINK, P. R. Effect of filling technique and root canal area on the percentage of guta-percha in laterally compacted root fillings. Internacional Endodontic Journal, v.42, n.9, p.719-726, 2009.

VENTURI, M. An ex vivo evaluation of a gutta-percha filling technique when used with two endodontic sealers: analysis of the filling of main and lateral canals. Journal of Endodontics, v.34, n.9, p.1105-1110, 2008.

VERSIANI, M. A.; PÉCORA, J. D.; DE SOUSA-NETO, M. D. Pulp pathosis in inlayed teeth of the ancient Mayas: a microcomputed tomography study. Internacional Endodontic Journal, v.44, n.11, p.1000-1004, 2011. 
VERSIANI, M. A.; PÉCORA, J. D.; DE SOUSA-NETO, M. D. The anatomy of tworooted mandibular canines determined using micro-computed tomography. Internacional Endodontic Journal, v.44, n.7, p.682-687, 2011a.

VERSIANI, M. A.; CARVALHO-JUNIOR, J. R.; PADILHA, M. I.; LACEY, S.; PASCON, E. A.; SOUSA-NETO, M. D. A comparative study of physicochemical properties of AH Plus and Epiphany root canal sealants. Internacional Endodontic Journal, v.39, n.6, p.464-471, 2006.

VERTUCCI, F. J. Root canal morphology and its relationship to endodontic procedures. Endodontic Topics, v.10, n.1, p.23-29, 2005.

VIER-PELISSER, F. V.; DUMMER, P. M. H.; BRYANT, S.; MARCA, C.; SÓ, M. V. R.; FIGUEIREDO, J. A. P. The anatomy of the root canal system of three-rooted maxillary premolars analysed using higher solution computed tomography. Internacional Endodontic Journal, v.43, n.12, p.1122-1131, 2010.

ZHOU, H-M.; SHEN, Y.; ZHENG, W.; LI. L.; ZHENG, Y-F.; HAAPASALO, M. Physical properties of 5 root canal sealers. Journal of Endodontics, v.39, n.10, p.1281-1286, 2013.

WU, M-K.; R'ORIS, A.; BARKIS, D.; WESSELINK, P. R. Prevalence and extent of long oval canals in the apical third. Oral Surgery Oral Medicine Oral Pathology Oral Radiology Endodontics, v.89, n.6, p.739-743, 2000.

WU, M-K.; KAŠT'ÁKOVÁ, A.; WESSELINK, P. R. Quality of cold and warm guttapercha fillings in oval canals in mandibular premolars. International Endodontic Journal, v.34, n.6, p.485-491, 2001.

WU, M-K.; DUMMER, P. M. H.; WESSELINK, P. R. Consequences of and strategies to deal with residual post-treatment root canal infection. Internacional Endodontic Journal, v.39, n.35, p.343-356, 2006.

YIN, X.; CHEUNG, G. S.; ZHANG, C.; MASUDA, Y. M.; KIMURA, Y.; MATSUMOTO, $\mathrm{K}$. Micro-computed tomographic comparison of nickel-titanium rotary versus traditional instruments in c-shaped root canal system. Journal of Endodontics, v.36, n. 4 , p.708-712, 2010. 
Apêndices 

Apêndice 1. Valores originais dos volumes de cimento endodôntico em relação aos diferentes cimentos obturadores e técnica obturadora

\begin{tabular}{|c|c|c|}
\hline \multirow{2}{*}{$\begin{array}{c}\text { Cimento } \\
\text { Endodôntico }\end{array}$} & \multicolumn{2}{|c|}{ Técnica } \\
\hline & Passiva & Ativa \\
\hline \multirow{8}{*}{ AH Plus } & 0,11935 & 0,10654 \\
\hline & 0,11415 & 0,11661 \\
\hline & 0,12893 & 0,10789 \\
\hline & 0,11973 & 0,10766 \\
\hline & 0,10055 & 0,11398 \\
\hline & 0,11443 & 0,1029 \\
\hline & 0,10521 & 0,10327 \\
\hline & 0,11922 & 0,10667 \\
\hline \multirow{8}{*}{ Endofill } & 0,11964 & 0,08362 \\
\hline & 0,09751 & 0,09446 \\
\hline & 0,10151 & 0,10496 \\
\hline & 0,10163 & 0,11441 \\
\hline & 0,10703 & 0,10385 \\
\hline & 0,10682 & 0,08369 \\
\hline & 0,11502 & 0,10697 \\
\hline & 0,11197 & 0,10055 \\
\hline \multirow{8}{*}{ Sealapex } & 0,09358 & 0,09933 \\
\hline & 0,09921 & 0,09141 \\
\hline & 0,09988 & 0,08211 \\
\hline & 0,10352 & 0,08587 \\
\hline & 0,10983 & 0,11281 \\
\hline & 0,10395 & 0,11468 \\
\hline & 0,10119 & 0,09799 \\
\hline & 0,10019 & 0,09734 \\
\hline \multirow{8}{*}{ Sealer 26} & 0,14904 & 0,10071 \\
\hline & 0,13462 & 0,0977 \\
\hline & 0,13651 & 0,10275 \\
\hline & 0,10649 & 0,10188 \\
\hline & 0,11462 & 0,08072 \\
\hline & 0,10706 & 0,08991 \\
\hline & 0,12028 & 0,11207 \\
\hline & 0,10772 & 0,08609 \\
\hline
\end{tabular}


Apêndice 2. Valores originais dos volumes de guta-percha em relação aos diferentes cimentos obturadores e técnica obturadora

\begin{tabular}{|c|c|c|}
\hline \multirow{2}{*}{$\begin{array}{c}\text { Cimento } \\
\text { Endodôntico }\end{array}$} & \multicolumn{2}{|c|}{ Técnica } \\
\hline & Passiva & Ativa \\
\hline \multirow{8}{*}{ AH Plus } & 0,21283 & 0,27893 \\
\hline & 0,31715 & 0,23629 \\
\hline & 0,30923 & 0,29544 \\
\hline & 0,2935 & 0,34267 \\
\hline & 0,38425 & 0,31105 \\
\hline & 0,32285 & 0,30609 \\
\hline & 0,36783 & 0,29785 \\
\hline & 0,26383 & 0,48358 \\
\hline \multirow{8}{*}{ Endofill } & 0,23551 & 0,26427 \\
\hline & 0,21962 & 0,30178 \\
\hline & 0,22937 & 0,23707 \\
\hline & ,024512 & 0,23751 \\
\hline & 0,29011 & 0,23782 \\
\hline & 0,31773 & 0,29217 \\
\hline & 0,27473 & 0,31934 \\
\hline & 0,31298 & 0,2793 \\
\hline \multirow{8}{*}{ Sealapex } & 0,25758 & 0,29718 \\
\hline & 0,27838 & 0,26889 \\
\hline & 0,26027 & 0,29514 \\
\hline & 0,31376 & 0,27958 \\
\hline & 0,32066 & 0,33055 \\
\hline & 0,27238 & 0,39525 \\
\hline & 0,28256 & 0,27455 \\
\hline & 0,29869 & 0,39249 \\
\hline \multirow{8}{*}{ Sealer 26} & 0,39368 & 0,34418 \\
\hline & 0,38039 & 0,32471 \\
\hline & 0,23893 & 0,27694 \\
\hline & 0,39877 & 0,35075 \\
\hline & 0,28375 & 0,32943 \\
\hline & 0,24197 & 0,30099 \\
\hline & 0,33456 & 0,36079 \\
\hline & 0,23284 & 0,33721 \\
\hline
\end{tabular}


Anexos 

Anexo 1. Aprovação do Comitê de Ética em Pesquisa.

\section{FACULDADE DE ODONTOLOGIA DE RIBEIRÃO PRETO/ FORP/ USP}

\section{PARECER CONSUBSTANCIADO DO CEP}

\section{DADOS DO PROJETO DE PESQUISA}

Título da Pesquisa: Avaliação da qualidade de obturação utilizando quatro diferentes cimentos com técnica de condensação lateral ativa e passiva

Pesquisador: Vanessa Lessa Cavalcanti de Araújo

Área Temática:

Versão: 1

CAAE: 20872013.0 .0000 .5419

Instituição Proponente: Universidade de Sao Paulo

Patrocinador Principal: Financiamento Próprio

\section{DADOS DO PARECER}

Número do Parecer: 404.419

Data da Relatoria: 17/09/2013

Apresentação do Projeto:

Projeto apresentado de maneira clara e direta, com objetivos bem definidos, em sintonia com pesquisas na literatura informada. Para realização da pesquisa serão utilizados 64 dentes incisivos centrais superiores humanos, com o comprometimento do Banco de Dentes Humanos da FORP-USP.

\section{Objetivo da Pesquisa:}

Observar se o volume dos diferentes cimentos formarão uma película de espessura mínima, afim de que fique adjacente às paredes dos canais e não ocasione a formação de grandes espaços vazios após a solubilização dos cimentos, deixando favorável à recontaminação do sistema de canais radiculares.

O objetivo deste estudo in vitro será de comparar a quantidade de guta-percha e de cimento endodôntico, por meio da técnica de obturação da condensação lateral ativa e da passiva, no milímetro apical da obturação, utilizando quatro cimentos diferentes, sendo eles: o cimento Endofill, à base de óxido de zinco e eugenol, o Sealer 26 e o Sealapex, que contém hidróxido de cálcio e o AH Plus, que é um cimento resinoso.

\section{Avaliação dos Riscos e Benefícios:}

Como benefício: Obsevar a efetividade do selamento no milímetro apical após a obturação,

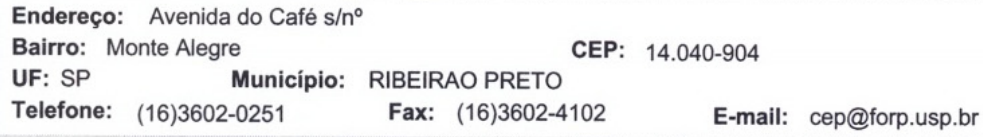




\section{FACULDADE DE ODONTOLOGIA DE RIBEIRÃO Q Platoforma PRETO/ FORP/ USP}

Continuaçăo do Parecer: 404.419

diminuindo assim, a infiltração apical e, consequentemente o insucesso endodôntico.

O trabalho não apresenta riscos previsiveis.

\section{Comentários e Considerações sobre a Pesquisa:}

O projeto apresenta-se bem fundamentado objetivando a comparação do volume de cimento e guta-percha dos diferentes grupos de cimentos e técnicas de obturação utilizadas. Nesse caso, se a amostra apresentar distribuição normal, será utilizado o teste ANOVA, seguido de teste de Tukey. O trabalho apresenta duas variáveis: o uso de quatro tipo de cimentos diferentes (Endofill, Sealer 26, Sealapex, AH Plus) e a utilização de duas técnicas de obturação (condensação lateral ativa e passiva).

\section{Considerações sobre os Termos de apresentação obrigatória:}

Apresentados adequadamente.

\section{Recomendações:}

Tempo verbal do resumo primeira linha: "O objetivo do presente estudo in vitro foi comparar..." O estudo será realizado e não foi.

Incluir o nome dos demais pesquisadores

\section{Conclusões ou Pendências e Lista de Inadequações:}

O Pesquisador deverá atender as recomendações acima. Diante do exposto, O Comitê de Ética em Pesquisa ¿ CEP/FORP manifesta-se por aguardar o atendimento às questões acima para emissão de seu parecer final. As pendências devem ser respondidas exclusivamente pelo pesquisador responsável no prazo de 60 dias, a partir da data de envio do parecer pelo CEP. Após este prazo o protocolo será arquivado. Solicita-se ainda que as respostas sejam enviadas de forma ordenada, conforme os itens das considerações deste parecer, indicando-se a localização das possíveis alterações deste parecer e também a localização das alterações no projeto.

\section{Situação do Parecer:}

Pendente

\section{Necessita Apreciação da CONEP:}

Não

Considerações Finais a critério do CEP:

Conforme deliberado na $152^{\mathrm{a}}$ sessão.

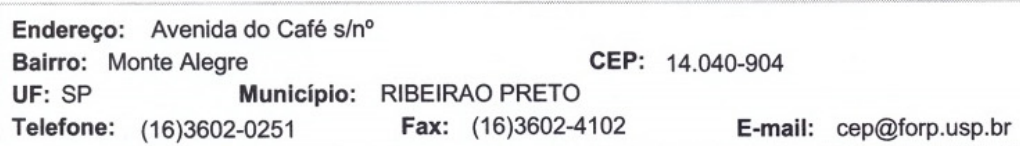




\section{FACULDADE DE ODONTOLOGIA DE RIBEIRÃO PRETO/ FORP/ USP}

Continuação do Parecer: 404.419

RIBEIRAO PRETO, 24 de Setembro de 2013

Assinador por:

JOSÉ TARCÍSIO LIMA FERREIRA

(Coordenador)

Endereço: Avenida do Café $\mathrm{s} / \mathrm{n}^{\circ}$

UF: SP

Município: RIBEIRAO PRETO

Telefone: (16)3602-0251

Fax: (16)3602-4102

E-mail: cep@forp.usp.br 
Anexo 2. Parâmetros de aquisição das projeções das imagens.

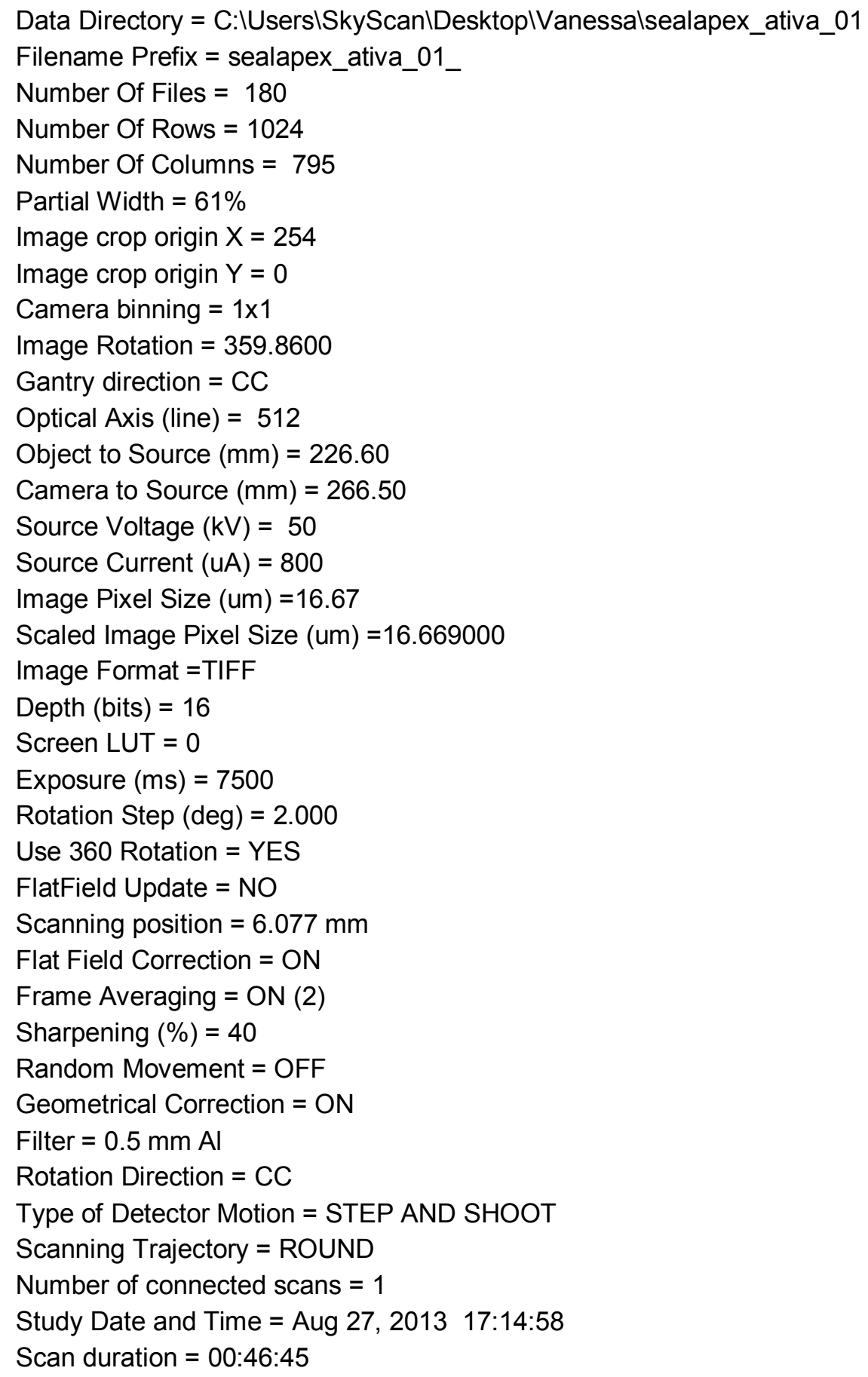


Anexo 3. Parâmetros de reconstrução (NRecon).

Reconstruction Program=NRecon

Program Version=Version: 1.6.6.0

Program Home Directory=C:ISkyScan1174ver2

Reconstruction engine=NReconServer

Engine version=Version: 1.6 .6

Reconstruction from batch $=$ Yes

Reconstruction servers= DOR-LABPECORA03

Option for additional F4F float format=OFF

Reconstruction mode $=$ Standard

Dataset Origin=SkyScan1174v2

Dataset Prefix=sealapex_ativa_01

Dataset Directory=C:IUsers|SkyScan|Desktop|Vanessalsealapex_ativa_01

Output Directory=C:IUsers|SkyScanlDesktoplVanessalsealapex_ativa_01/sealapex_ativa_01_Rec

Time and Date=Aug 30, 2013 11:07:45

First Section $=14$

Last Section $=970$

Reconstruction duration per slice (seconds) $=0.187043$

Total reconstruction time (957 slices) in seconds $=179.000000$

Postalignment=-3.00

Section to Section Step $=1$

Sections Count $=957$

Result File Type=BMP

Result File Header Length (bytes) $=1134$

Result Image Width (pixels) $=596$

Result Image Height (pixels) $=596$

Pixel Size (um) $=16.66900$

Reconstruction Angular Range (deg) $=360.00$

Use 180+=OFF

Angular Step $(\mathrm{deg})=2.0000$

Smoothing $=3$

Smoothing kernel=1 (Symmetrical boxcar)

Ring Artifact Correction $=5$

Draw Scales $=$ OFF

Object Bigger than FOV=OFF

Reconstruction from $\mathrm{ROI}=\mathrm{ON}$

ROI Top (pixels) $=683$

ROI Bottom (pixels) $=87$

ROI Left (pixels) $=97$

ROI Right (pixels) $=693$

$\mathrm{ROI}$ reference length $=795$

Filter cutoff relative to Nyquisit frequency $=100$

Filter type $=0$

Filter type meaning(1)=0: Hamming (Ramp in case of optical scanner); 1: Hann; 2: Ramp; 3: Almost Ramp;

Filter type meaning(2)=11: Cosine; 12: Shepp-Logan; [100,200]: Generalized Hamming, alpha=(iFilter100)/100

Undersampling factor=1

Threshold for defect pixel mask $(\%)=0$

Beam Hardening Correction $(\%)=15$

CS Static Rotation $(\mathrm{deg})=0.00$

Minimum for CS to Image Conversion $=0.012000$

Maximum for $\mathrm{CS}$ to Image Conversion $=0.500000$

HU Calibration=OFF

BMP LUT=0

Cone-beam Angle Horiz. $(\mathrm{deg})=3.349775$

Cone-beam Angle Vert. $(\mathrm{deg})=4.313870$ 